\title{
35. ORGANIC GEOCHEMISTRY OF SEDIMENTS FROM THE SOUTHERN CALIFORNIA BORDERLAND, DEEP SEA DRILLING PROJECT LEG 63 ${ }^{1}$
}

\author{
Bernd R. T. Simoneit, Institute of Geophysics and Planetary Physics, University of California, \\ Los Angeles, California \\ and
}

M. A. Mazurek, Department of Earth and Space Sciences, University of California, Los Angeles, California

\begin{abstract}
Selected core samples from the California Continental Borderland (Sites 467-469) were analyzed to evaluate the nature and composition of the lipids and kerogens in terms of their genetic origin and geological maturity.

The lipids were of a multiple origin. On the basis of the homolog distributions of the $n$-alkanes and $n$-fatty acids, with the shape and magnitude of the unresolved branched and cyclic hydrocarbons, and the structural and stereochemical compositions of the molecular markers, these lipids were derived from primary autochthonous marine (microbial), from allochthonous terrigenous (higher plant wax), and from recycled (geologically mature organic matter) sources.

The kerogens were composed of principally marine microbial detritus with a minor input of allochthonous terrestrial material. For the most part, the samples had undergone a thermal maturation according to a normal geothermal gradient, except in the proximity of intrusives. Such additional thermal stress was evident for the samples from Site 469 and to some extent for Site 467 at about a sub-bottom depth of 700 to 800 meters.
\end{abstract}

\section{INTRODUCTION}

The California Continental Borderland is an area of great geological complexity, and the clues to its Neogene history are to be found in the deep-sea sediments of this area. Recent, near-surface sediments from the California Bight and borderland contain organic matter derived from autochthonous production and from allochthonous sources such as natural petroleum seepage and influx of terrestrial detritus (Simoneit and Kaplan, 1980; Venkatesan et al., 1980). Thus it was of interest to follow these trends versus depth in the sedimentary record.

Sites 467 to 469 (Fig. 1), located in the California Continental Borderland, contain relatively thick sequences of nannofossil chalk, silty and dolomitic claystones, tuff, porcellanite, and thin sequences of clay and ooze with glauconite and vitric ash (Haq et al., 1979).

The outer southern California borderland may be another natural example of distinct regimes of thermal stress upon organic material (kerogen) within a localized marine setting, analogous to the case of the observed thermal alteration of Cretaceous black shale by basaltic intrusions in the eastern Atlantic (Simoneit et al., 1978).

Sites 468 and 469 are located on the Patton Ridge along the western edge of the borderland and are within $15 \mathrm{~km}$ of the inferred paleotrench of southern California (Table 1). Site 467 is situated at the base of the continental slope at the San Miguel Gap and is on the $\mathrm{Pa}$ cific plate, just west of the postulated paleotrench (Haq et al., 1979, table 1). All three sites have high heat-flow values, and the respective core lithologies show varying degrees of volcanic influence. Sites 467 and 468 contain

\footnotetext{
${ }^{1}$ Initial Reports of the Deep Sea Drilling Project, Volume 63.
}

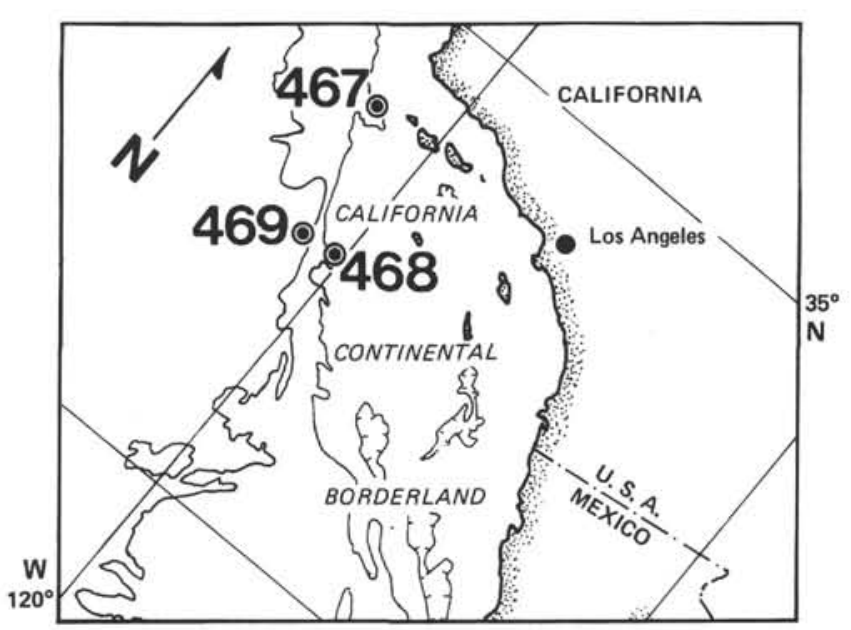

Figure 1. Location map of Sites 467 to 469 in the California Continental Borderland.

locally derived, middle Miocene (10-15 Ma) andesitic and dacitic tuffs and breccias, presumably formed after cessation of plate subduction (Haq et al., 1979). Hole 469 penetrated pillow basalt and contains zones of pumiceous tuff and diabase (Haq et al., 1979).

Thus we further characterized the organic matter (i.e., lipids and kerogen) by its chemical, elemental, and stable isotope $(\mathrm{C}$ and $\mathrm{H})$ compositions to evaluate the effects of differential heating or anomalous maturation resulting from high heat flow or localized volcanic emanations.

\section{EXPERIMENTAL METHODS}

\section{Lipids}

Lipids were removed from subsamples of the freeze-dried sediments by multiple mechanical extractions using shaker table agita- 


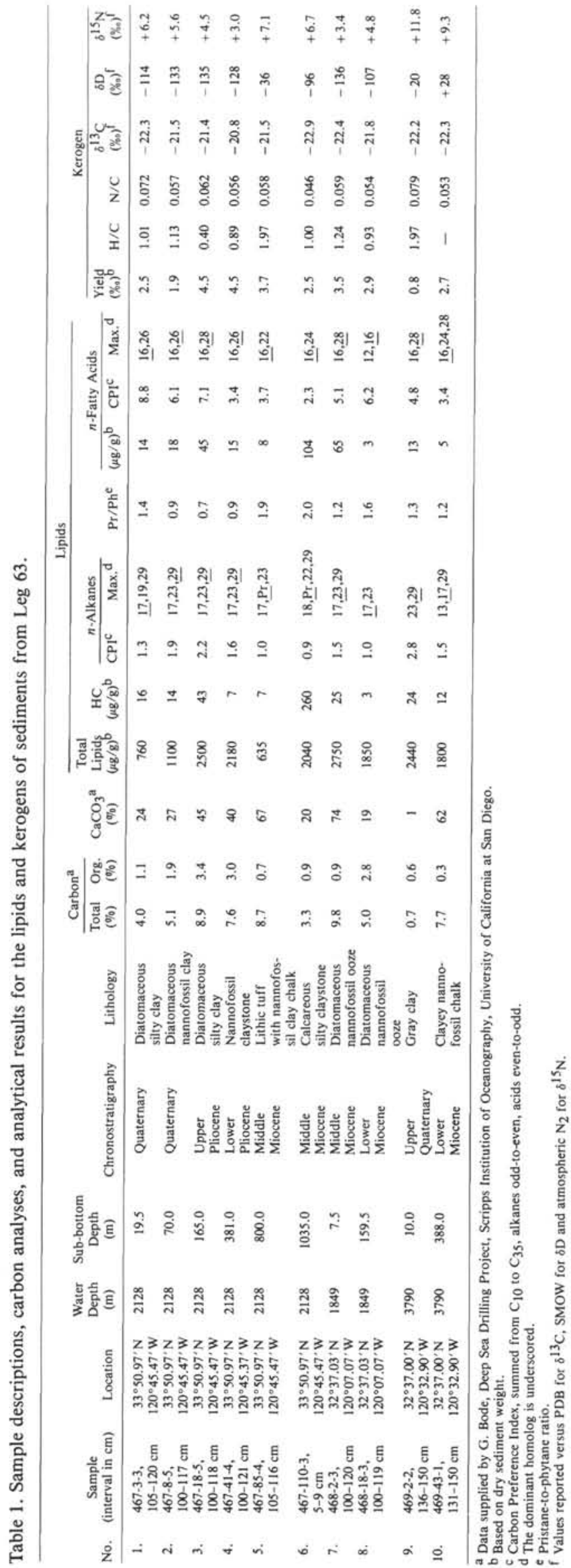

tion with an extraction medium of $150 \mathrm{ml}$ chloroform and methanol in a 1:1 ratio. The extracts were concentrated on a rotary evaporator and treated with $\mathrm{BF}_{3}$ in methanol to esterify free fatty acids. The extract was then subjected to thin-layer chromatography (TLC) using hexane and diethyl ether (9:1) as eluent. The bands corresponding to hydrocarbons, esters, and ketones were scraped off the TLC plate after development with iodine vapor, and eluted with methylene chloride. The hydrocarbon and combined ester and ketone fractions were analyzed by gas chromatography (GC) and gas chromatography-mass spectrometry (GC/MS).

The GC analyses were carried out on a Hewlett-Packard Model 5830 gas chromatograph using a $25-\mathrm{m} \times 0.20-\mathrm{mm}$ fused silica capillary column coated with SP-2100, programmed from $35^{\circ} \mathrm{C}$ to $280^{\circ} \mathrm{C}$ at $4^{\circ} \mathrm{C} / \mathrm{min}$. and using $\mathrm{He}$ carrier gas.

The GC/MS analyses were carried out on a Finnigan Model 4000 quadrupole mass spectrometer interfaced directly to a Finnigan Model 9610 gas chromatograph equipped with a $30-\mathrm{m} \times 0.25-\mathrm{mm}$ fused silica capillary column coated with SE-54. The GC conditions for the GC/MS analyses were like those for the analytical GC system. The mass spectrometric data were acquired and processed using a Finnigan-Incos Model 2300 data system.

\section{Kerogen}

The extracted residue was acidified at room temperature with 25 $\mathrm{ml}$ of $2 \mathrm{~N} \mathrm{HCl}$ (organically purified) to dissolve carbonates and labile sulfur compounds. All samples showed considerable effervescence; therefore two additional $2 \mathrm{~N} \mathrm{HCl}$ treatments were necessary for a period of two days to ensure complete removal. Samples were then washed repeatedly ( 10 times) with 200 -ml additions of doubly distilled water to remove extraneous ions. Silver nitrate solution was used to test for the presence of chloride ion.

Silicate dissolution was carried out by the addition of $200 \mathrm{ml}$ concentrated hydrofluoric acid $(60 \%)$. This step was repeated twice in order to exhaustively saturate with $\mathrm{HF}$ and thus completely decompose all silicate minerals. The nonsilicate residues were washed $(7$ times) with $150 \mathrm{ml}$ of doubly distilled water.

Residual humates were removed by the addition of $150 \mathrm{ml}$ of organically purified $0.2 \mathrm{~N} \mathrm{NaOH}$. Only samples 1 to 3 and 7 showed observable humates, and they were extracted another three times with $0.2 \mathrm{~N} \mathrm{NaOH}$. After base extraction, all remaining kerogen samples were washed 6 times by $200-\mathrm{ml}$ additions of doubly distilled water and then freeze dried. Aliquots $(6-10 \mathrm{mg})$ of the isolated kerogens were placed in preweighed, organically cleaned and annealed porcelain boats for ash determinations. They were inserted into a muffle furnace and very slowly brought up to $1000^{\circ} \mathrm{C}$ (time interval $-5 \mathrm{hr}$.); they were then held isothermally for $3 \mathrm{hr}$. Ash contents were determined by a final weighing and after the samples had completely cooled.

Combustions for the stable isotope analyses were carried out as follows. Kerogen aliquots $(6-11 \mathrm{mg})$ were placed into annealed quartz tubes containing organically cleaned silver envelopes and fired $\mathrm{CuO}$ wire. (Silver combines with pyrolyzed sulfides, and $\mathrm{CuO}$ provides the oxygen source during combustion in the evacuated and sealed quartz reaction vessels.) Reaction mixtures were combusted at $880^{\circ} \mathrm{C}$ for 2 hr. Replicate samples were prepared in order to provide a duplicate in the event of tube explosion during the combustion.

The quartz reaction vessels containing $\mathrm{CO}_{2}, \mathrm{~N}_{2}$, and $\mathrm{H}_{2} \mathrm{O}$ combustion products were opened under vacuum. The three gases were then separated in a CHN vacuum line by sequential freezing followed by revolatilization. Cold traps in thermal equilibrium with liquid nitrogen $\left(-196^{\circ} \mathrm{C}\right)$, dry ice with acetone $\left(-73^{\circ} \mathrm{C}\right)$, and, lastly, with hot water $\left(70^{\circ} \mathrm{C}\right)$ were used to retain the desired gaseous product in a condensed state. As $\mathrm{CO}_{2}$ and $\mathrm{H}_{2} \mathrm{O}$ were frozen within the liquid nitrogen cold trap, the sample $\mathrm{N}_{2}$ gas was isolated by passing it through a Toepler pump and into a calibrated volume manometer where the pressure of the $\mathrm{N}_{2}$ gas was measured (and later converted to $\mu \mathrm{mol}$ ). It was then transferred to a pyrex tube, in which it was sealed for subsequent mass spectrometric analysis. Gaseous $\mathrm{CO}_{2}$ was similarly isolated, measured, and stored after the cold trap temperature was raised to $-73^{\circ} \mathrm{C}$. The remaining $\mathrm{H}_{2} \mathrm{O}$ gas was warmed to $\sim 70^{\circ} \mathrm{C}$ and then reduced to $\mathrm{H}_{2}$ gas by passing it through a uranium furnace maintained at $780^{\circ} \mathrm{C}$ and under vacuum. The $\mathrm{H}_{2}$ gas was then measured volumetrically and sealed into a pyrex tube.

Stable isotope mass spectrometery of the isolated $\mathrm{CO}_{2}, \mathrm{~N}_{2}$, and $\mathrm{H}_{2}$ gases was performed on a Varian MAT Model 250 triple-collecting mass spectrometer. Correction factors established by Craig (1957) 
were applied to the directly measured $\mathrm{CO}_{2}$ mass numbers. The $\mathrm{CO}_{2}$ gas was measured relative to the Pee Dee Belemnite (PDB) standard, the $\mathrm{H}_{2}$ gas was compared to Standard Mean Ocean Water (SMOW), and the $\mathrm{N}_{2}$ gas was referenced to atmospheric nitrogen. Isotopic deviation from the relative values established by these reference compounds was expressed in the conventional " $\delta$ " notation in parts-permil, where:

$$
\delta(\%)=\left[\frac{R_{\text {sample }}-R_{\text {standard }}}{R_{\text {standard }}}\right] \times 1000
$$

and

$R={ }^{13} \mathrm{C} /{ }^{12} \mathrm{C}$ for carbon,

$R=\mathrm{D} / \mathrm{H}$ for hydrogen, and

$R={ }^{15} \mathrm{~N} /{ }^{14} \mathrm{~N}$ for nitrogen.

\section{RESULTS AND DISCUSSION}

\section{Lipids}

The lipid yields were high, and the concentrations of the hydrocarbons were generally in excess of the fatty acids (Table 1). Ketones were present as minor components only, with 6,10,14-trimethylpentadecan-2-one as the major analog.

The distribution diagrams for the $n$-alkanes and $n$-fatty acids of the Site 467 samples are found in Figure 2 . The $n$-alkanes of the samples back to the early Pliocene exhibit an essentially trimodal distribution, with maxima at $\mathrm{C}_{17}, \mathrm{C}_{23}$, and $\mathrm{C}_{29}$, no carbon number predominance $<C_{26}$, a strong odd carbon number predominance $>C_{26}$, and a range from $C_{10}$ to $C_{33}$ (Fig. 2A-D). The sources of the homologs $<\mathrm{C}_{26}$ are from primarily degraded microbial detritus of an autochthonous origin, and the homologs $>\mathrm{C}_{26}$ are derived from allochthonous terrigenous plant waxes (Simoneit, 1978; 1979a). The $n$-alkanes of the lithic tuff (467-85-4, Fig. 2E) exhibit a bimodal distribution ranging from $C_{11}$ to $C_{31}$, with no carbon number predominance and maxima at $\mathrm{C}_{17}$ and $\mathrm{C}_{23}$. This distribution is indicative of a thermally degraded lipid residue (Simoneit 1978, 1979a). The bottom sample in the diatom-nannofossil ooze (Fig. 2F) exhibits $n$-alkanes derived from microbial residues $\left(<\mathrm{C}_{26}\right)$ and higher plant waxes $\left(>\mathrm{C}_{26}\right)$. The pristate-to-phytane ratios of the upper samples (Fig. 2A-D) are approximately 1.0 (cf., Table 1), indicating incomplete euxinic conditions (Didyk et al., 1978) where the rate of influx of organic detritus did not fully deplete the oxygen in the sedimentary environment. This interpretation, however, must be considered with caution, because a significant portion of the lipids is interpreted to be not syngenetic but derived from geologically older material. Thus the $\mathrm{Pr} / \mathrm{Ph}$ may not reflect the true sedimentary conditions. The $\mathrm{Pr} / \mathrm{Ph}$ of the two lowest samples (Fig. $2 \mathrm{E}, \mathrm{F}$ ) is about 2.0 , indicating oxic sedimentary conditions (Didyk et al., 1978). The dominance of pristane in these two samples may indicate the major contribution of diatoms to the lipids. Perylene, another indicator of anoxic conditions of sedimentation (Simoneit, 1979b; Didyk et al., 1978), was detected as a major lipid component in Sections 467-8-5, 467-18-5, 467-41-4, 467-854 , and 467-110-3 (Table 2).
The $n$-fatty acids of the upper samples (Fig. 2G-J) exhibit bimodal distributions, with a strong even-to-odd carbon number predominance, a range from $\mathrm{C}_{10}-\mathrm{C}_{32}$, and maxima at $\mathrm{C}_{16}$ and $\mathrm{C}_{26}$ or $\mathrm{C}_{28}$. The homologs $<\mathrm{C}_{22}$ are primarily of an autochthonous microbial origin ( $\mathrm{Si}$ moneit, 1975) and the homologs $>\mathrm{C}_{22}$, when considered in conjunction with the respective $n$-alkane distributions, are further markers of allochthonous higher plant lipids (Simoneit, 1975, 1978). The $n$-fatty acids of Sample 467-85-4 (Fig. 2K) exhibit an essentially unimodal distribution, with strong even-to-odd carbon number predominance, a range from $C_{10}$ to $C_{24}$, and the major maximum at $\mathrm{C}_{16}$. This distribution is typical of microbial residues (Simoneit 1975, 1978). The $n$-fatty acids of Sample 467-110-3 (Fig. 2L) exhibit a bimodal distribution, with an even-to-odd carbon number predominance, range from $C_{10}$ to $C_{32}$, and maxima at $C_{16}$ and $\mathrm{C}_{24}$. This distribution is of a mixed origin from microbial residues and to a lesser extent from terrestrial higher plant wax (Simoneit, 1975, 1978). A minor amount of dehydroabietic acid was detected in some of the samples (Fig. 2), indicating some allochthonous influx of resinous plant detritus (Simoneit, 1977).

The distribution diagrams for the $n$-alkanes and $n$-fatty acids of the samples from Sites 468 and 469 are found in Fig. 3. The $n$-alkanes of Sample 468-2-3, 100-120 cm exhibit a polymodal distribution, with maxima at $\mathrm{C}_{12}, \mathrm{C}_{17}, \mathrm{C}_{23}$, and $\mathrm{C}_{29}$, range from $\mathrm{C}_{10}$ to $\mathrm{C}_{33}$, and a strong odd carbon number predominance above $\mathrm{C}_{26}$ (Fig. 3A). The homologs $<\mathrm{C}_{26}$ are of a primarily autochthonous microbial origin and those $>\mathrm{C}_{26}$ are derived from allochthonous vascular plant waxes (Simoneit, 1978, 1979a). In the case of Sample 468-18-3, 100$119 \mathrm{~cm}$ the distribution is bimodal, ranging from $\mathrm{C}_{11}$ to $\mathrm{C}_{31}$, with maxima at $\mathrm{C}_{17}$ and $\mathrm{C}_{23}$, and essentially no carbon number predominance (Fig. 3B). This distribution may be indicative of a partially degraded microbial lipid residue, and it is the same as for Sample 467-85-4, 105$116 \mathrm{~cm}$ in the lithic tuff section.

The $n$-alkanes of Sample 469-2-2, $150 \mathrm{~cm}$ reflect a primarily allochthonous terrigenous origin from plant waxes by the dominance of the odd carbon number homologs $>\mathrm{C}_{26}$ and maximum at $\mathrm{C}_{29}$ (Fig. 3C). The minor maximum at $\mathrm{C}_{23}$ and homologs from $\mathrm{C}_{10}$ through $\mathrm{C}_{26}$ are derived from degraded microbial lipids. In the case of Sample 469-43-1, 131-150 cm, located near the diabase sill, the distribution of the $n$-alkanes is polymodal, with maxima at $\mathrm{C}_{13}, \mathrm{C}_{17}$, and $\mathrm{C}_{29}$, ranging from $\mathrm{C}_{10}$ to $\mathrm{C}_{33}$, with a strong odd-to-even carbon number predominance $>\mathrm{C}_{26}$ (Fig. 3D). The major homologs $<\mathrm{C}_{26}$ are derived from partially degraded autochthonous microbial detritus, where the cluster at $C_{13}$ may be contamination from diesel oil used on the core catcher. The homologs $>\mathrm{C}_{26}$ are derived from allochthonous higher plant waxes.

The $\mathrm{Pr} / \mathrm{Ph}$ of the samples from Sites 468 and 469 are about 1.2 or greater (Table 1), indicating oxic sedimentary environments (Didyk et al., 1978). Perylene was detectable as a minor component in Sections 468-2-3, 469-2-2, and 469-43-1 only (Table 2). It is another in- 

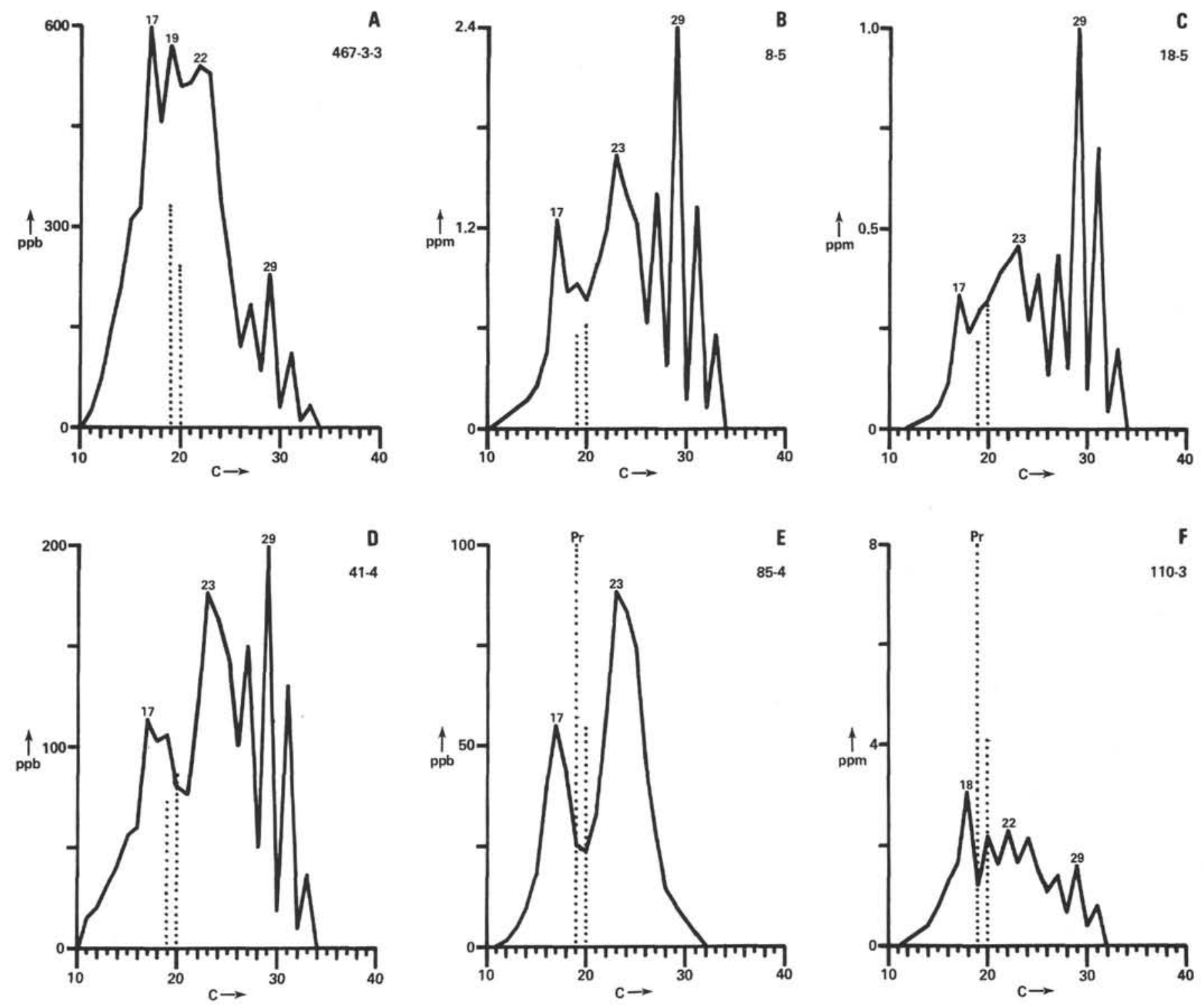

Figure 2. Distribution diagrams for the $n$-alkanes (A-F) and $n$-fatty acids (G-L) of the samples from Site 467 . ( $\ldots$ indicates isoprenoids; --- , dehydroabietic acid; C, carbon numbers). A, G: Sample 467-3-3, 105-120 cm, B, H: Sample 467-8-5, 100-117 cm, C, I: Sample 467-18-5, 100-118 cm, D, J: Sample 467-41-4, 100-121 cm, E, K: Sample 467-85-4, 105-116 cm, and F, L: Sample 467-110-3, 5-9 cm.)

dicator of anaerobic conditions of sedimentation $(\mathrm{Si}-$ moneit, 1979b; Didyk et al. 1978).

The $n$-fatty acids of Sample $468-18-3,100-119 \mathrm{~cm}$ range from $C_{10}$ to $C_{24}$, with a strong even-to-odd carbon number predominance and maximum at $\mathrm{C}_{16}$ (Fig. 3F). This is typical of a microbial origin. The $n$-fatty acids of the other three samples (Fig. 3E, G, H) range from $C_{10}$ to $\mathrm{C}_{34}$, with a strong even-to-odd carbon number predominance and bimodal distributions, with maxima at $\mathrm{C}_{16}$ and $\mathrm{C}_{28}$. The homologs $<\mathrm{C}_{22}$ are of an autochthonous microbial origin and those $>\mathrm{C}_{22}$, when considered with the $n$-alkanes $>\mathrm{C}_{26}$, are of an allochthonous origin from higher plant wax. A trace amount of dehydroabietic acid was detected in the surface sediments only, indicating a very minor influx of allochthonous detritus from resinous plants (Simoneit, 1977).

\section{Molecular Markers}

The concentrations of the $n$-alkylcyclohexanes, the extended diterpanes, the triterpenoids, and the steranes with sterenes are given in Table 2. Major sterane and triterpane concentrations were encountered in Sections 467-8-5, 467-18-5, 467-41-4, and 467-110-3.

Microbial markers in the form of $n$-alkylcyclohexanes were present, and their distributions are found in Figure 4. All samples, except 467-85-4, 105-116 cm, have similar distributions with maxima at $C_{21}$, no carbon number predominance, and an approximate range from $C_{13}$ to $C_{25}$. The exception (467-85-4) has a maximum at $\mathrm{C}_{18}$ and narrower range from $\mathrm{C}_{14}$ to $\mathrm{C}_{23}$. These compounds are general indicators of microbial detrital lipids (Simoneit, 1978, 1980). 

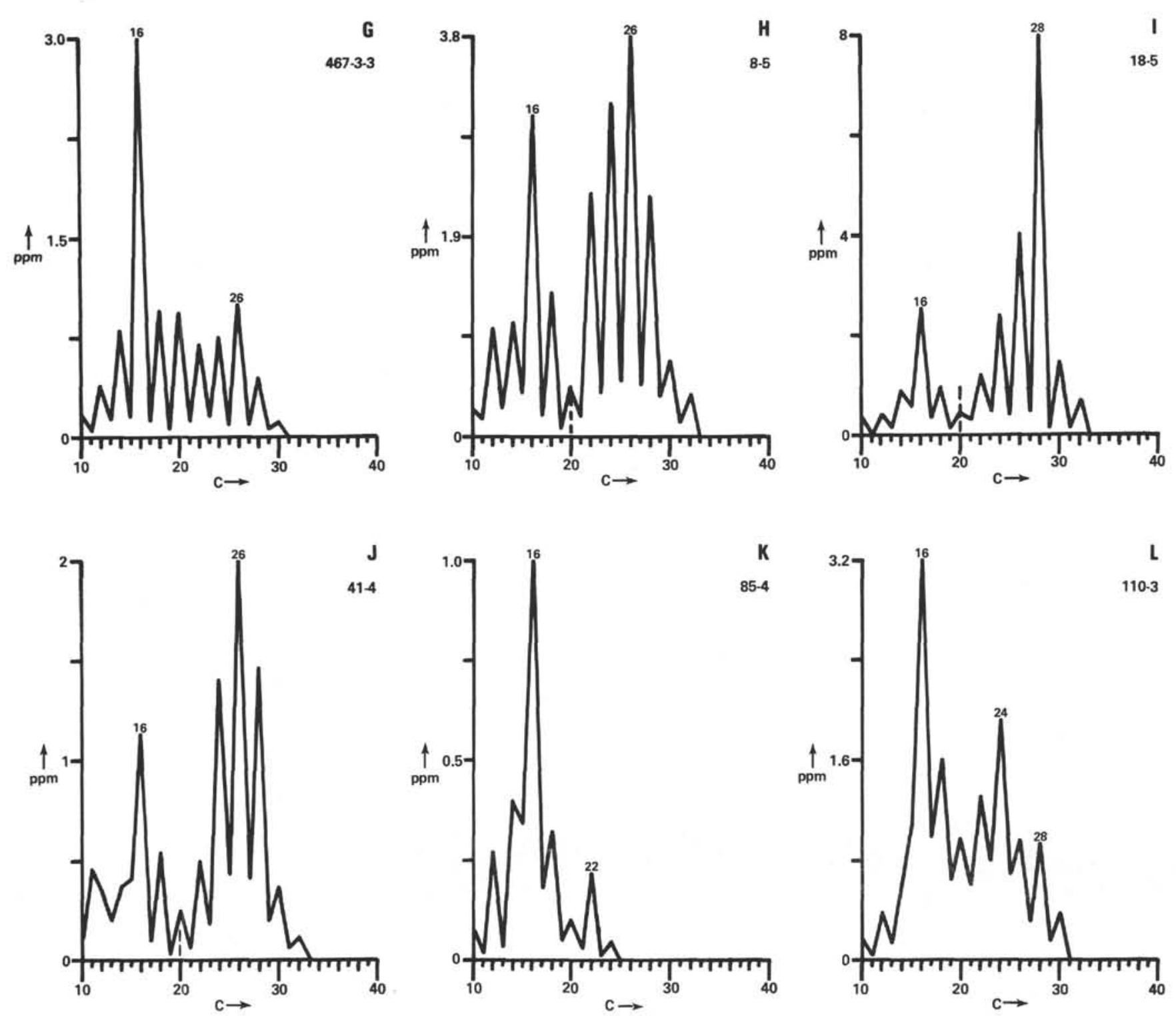

Figure 2. (Continued).

Table 2. Approximate concentrations of some molecular markers of sediments from Leg 63.

\begin{tabular}{|c|c|c|c|c|c|}
\hline Section & $\begin{array}{l}\text { Perylene } \\
(\mathrm{ng} / \mathrm{g})^{\mathrm{a}}\end{array}$ & $\begin{array}{l}\text { Alkyl- } \\
\text { cyclohexanes } \\
\text { (ng/g) }\end{array}$ & $\begin{array}{c}\text { Extended } \\
\text { Diterpanes } \\
\text { (ng/g) }\end{array}$ & $\begin{array}{c}\text { Triterpenoids } \\
\text { (ng/g) }\end{array}$ & $\begin{array}{c}\text { Steranes } \\
\text { (ng/g) }\end{array}$ \\
\hline \multicolumn{6}{|l|}{ Site 467} \\
\hline 1. $3-3$ & n.d. ${ }^{b}$ & 130 & 800 & 1200 & 250 \\
\hline 2. $8-5$ & 1000 & 105 & 660 & 1800 & 830 \\
\hline 3. $18-5$ & 3200 & 48 & 340 & 930 & 22,000 \\
\hline 4. $41-4$ & 900 & 82 & 100 & 190 & 460 \\
\hline 5. $85-4$ & 30 & 27 & 20 & 70 & 130 \\
\hline 6. $110-3$ & 200 & 840 & 380 & 2040 & 9600 \\
\hline \multicolumn{6}{|l|}{ Site 468} \\
\hline 7. $2-3$ & 100 & 170 & 190 & 300 & n.d. \\
\hline 8. $18-3$ & n.d. & - & - & - & - \\
\hline \multicolumn{6}{|l|}{ Site 469} \\
\hline 9. $2-2$ & 10 & 730 & 270 & 530 & 95 \\
\hline 10. $43-1$ & 20 & - & - & - & - \\
\hline
\end{tabular}

a Based on dry sediment weight.

$\mathrm{b}_{\text {n.d. }}=$ not detected.
The relative distributions based on the $\mathrm{m} / \mathrm{z} 191$ mass chromatograms of the extended diterpanes and triterpenoids are found in Figure 5. The extended diterpanes (Structure I) $)^{2}$ range from $\mathrm{C}_{20} \mathrm{H}_{36}\left(\mathrm{I}, \mathrm{R}=\mathrm{C}_{2} \mathrm{H}_{5}\right.$ ) to $\mathrm{C}_{26} \mathrm{H}_{48}$ (I, $\mathrm{R}=\mathrm{C}_{8} \mathrm{H}_{17}$ ) with a maximum at $\mathrm{C}_{23} \mathrm{H}_{42}$. In some samples, the range extends to $\mathrm{C}_{29} \mathrm{H}_{54}$ and the homologs $>\mathrm{C}_{26} \mathrm{H}_{48}$ are resolved into two diastereomers. The distribution patterns of the extended diterpanes, when considered with the triterpane distributions, are similar to those of shallow sediment samples from the Southern California Bight (Simoneit and Kaplan, 1980).

The triterpenoids (Fig. 5) consisted of primarily the geologically mature hydrocarbons of the $17 \alpha(\mathrm{H})$-hopane series (II), with minor amounts of $17 \beta(\mathrm{H})$-hopanes and $17 \beta(\mathrm{H})$-moretanes. The extended $17 \alpha(\mathrm{H})$-hopanes

${ }^{2}$ Hereafter, roman numerals following chemical species refer to structures illustrated in the Appendix. 

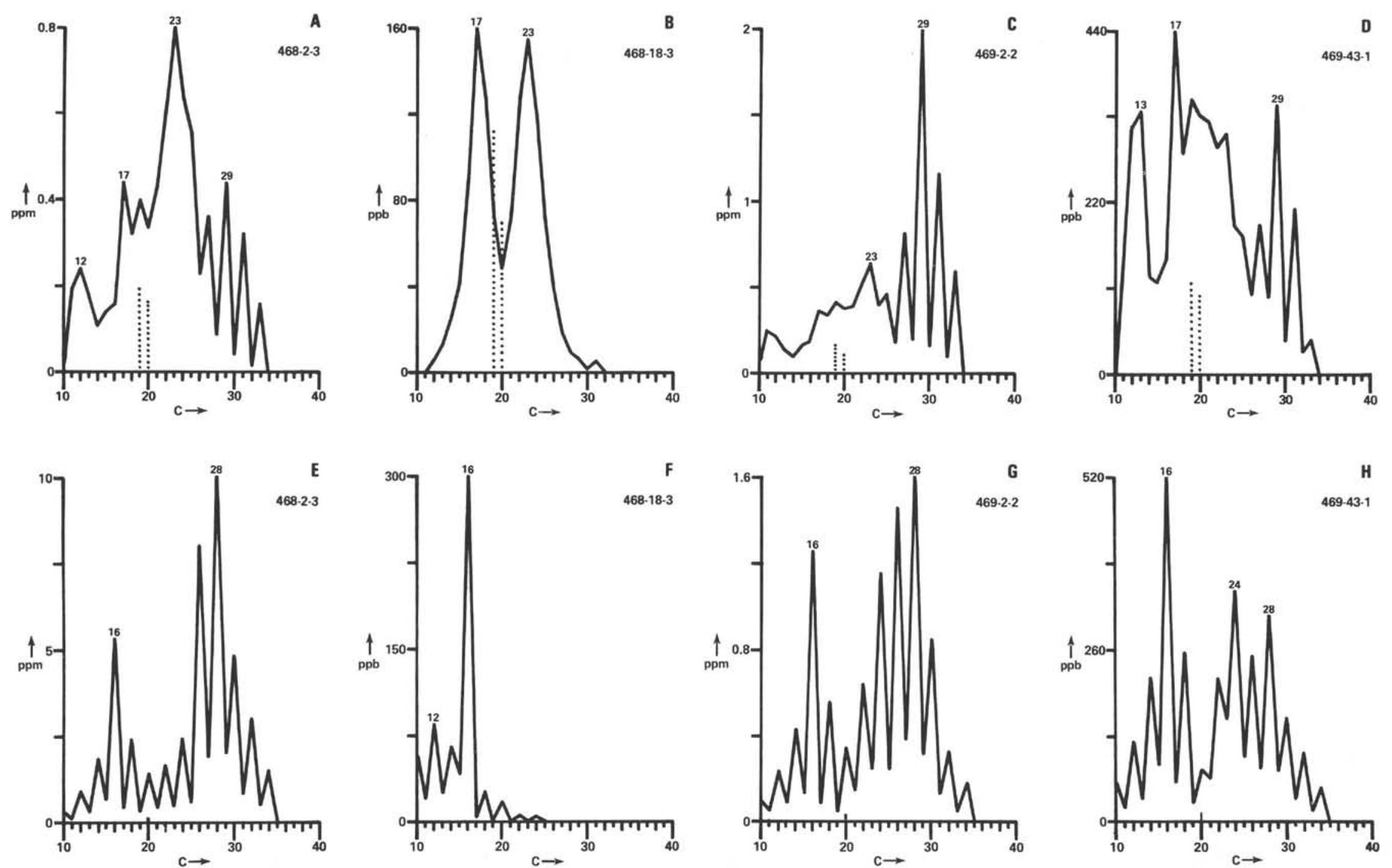

Figure 3. Distribution diagrams for the $n$-alkanes (A-D) and $n$-fatty acids (E-H) of the samples from Sites 468 and 469 . ( ... indicates isoprenoids; - - - dehydroabietic acid. A, E: Sample 468-2-3, 100-120 cm, B, F: Sample 468-18-3, 110-119 cm, C, G: Sample 469-2-2, 136-150 cm, and D, H: Sample 469-43-1, 131-150 cm.) 

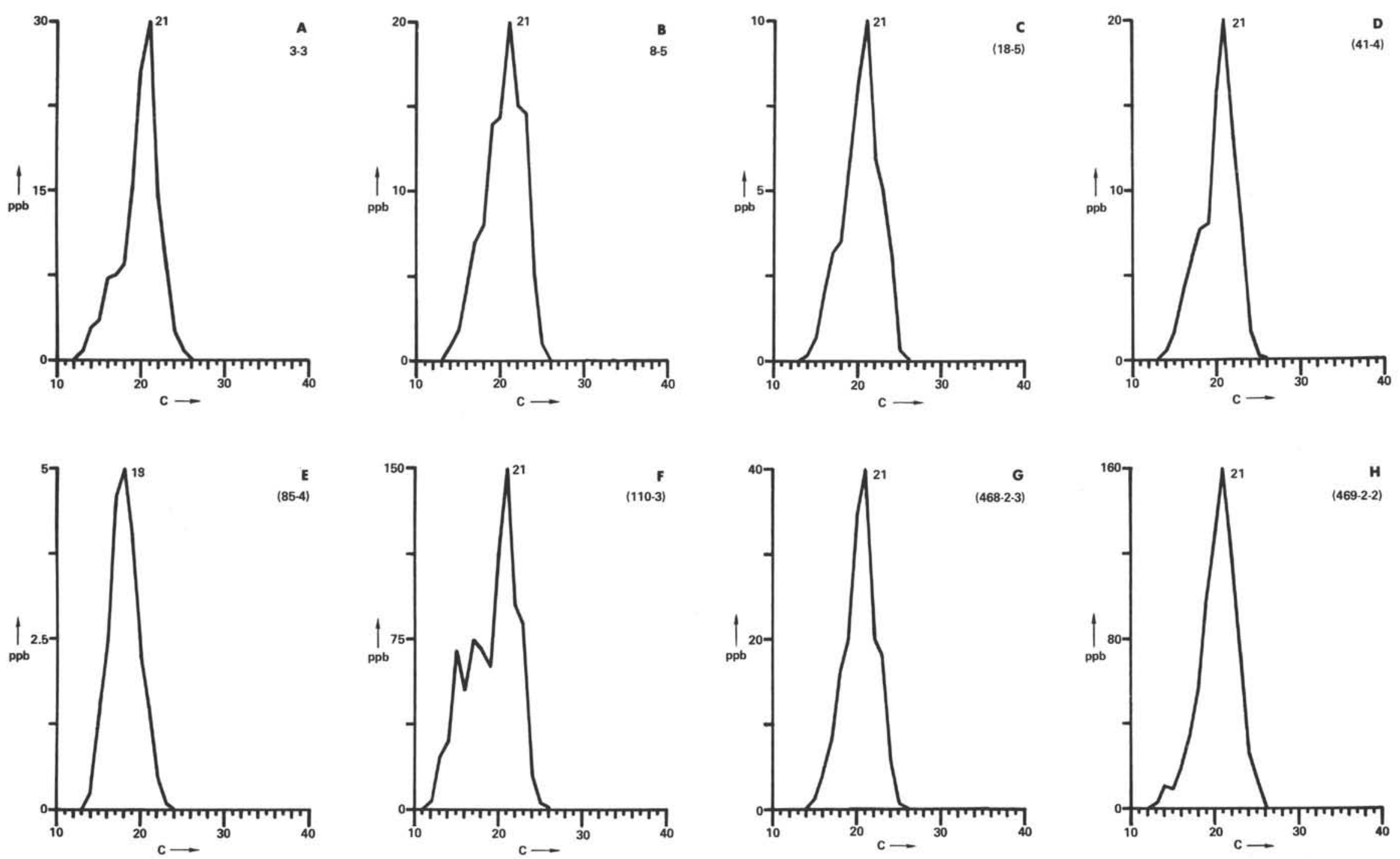

Figure 4. Distribution diagrams for the $n$-alkylcyclohexanes of the samples from Sites 467 through 469 . A. Sample 467-3-3, 105-120 cm; B. Sample 467-8-5, 100-117 cm; C. Sample 46718-5, 100-118 cm; D. Sample 467-41-4, 100-121 cm; E. Sample 467-85-4, 105-116 cm; F. Sample 467-110-3, 5-9 cm; G. Sample 468-2-3, 110-120 cm; and H. Sample 469-2-2, 136-150 cm.) 

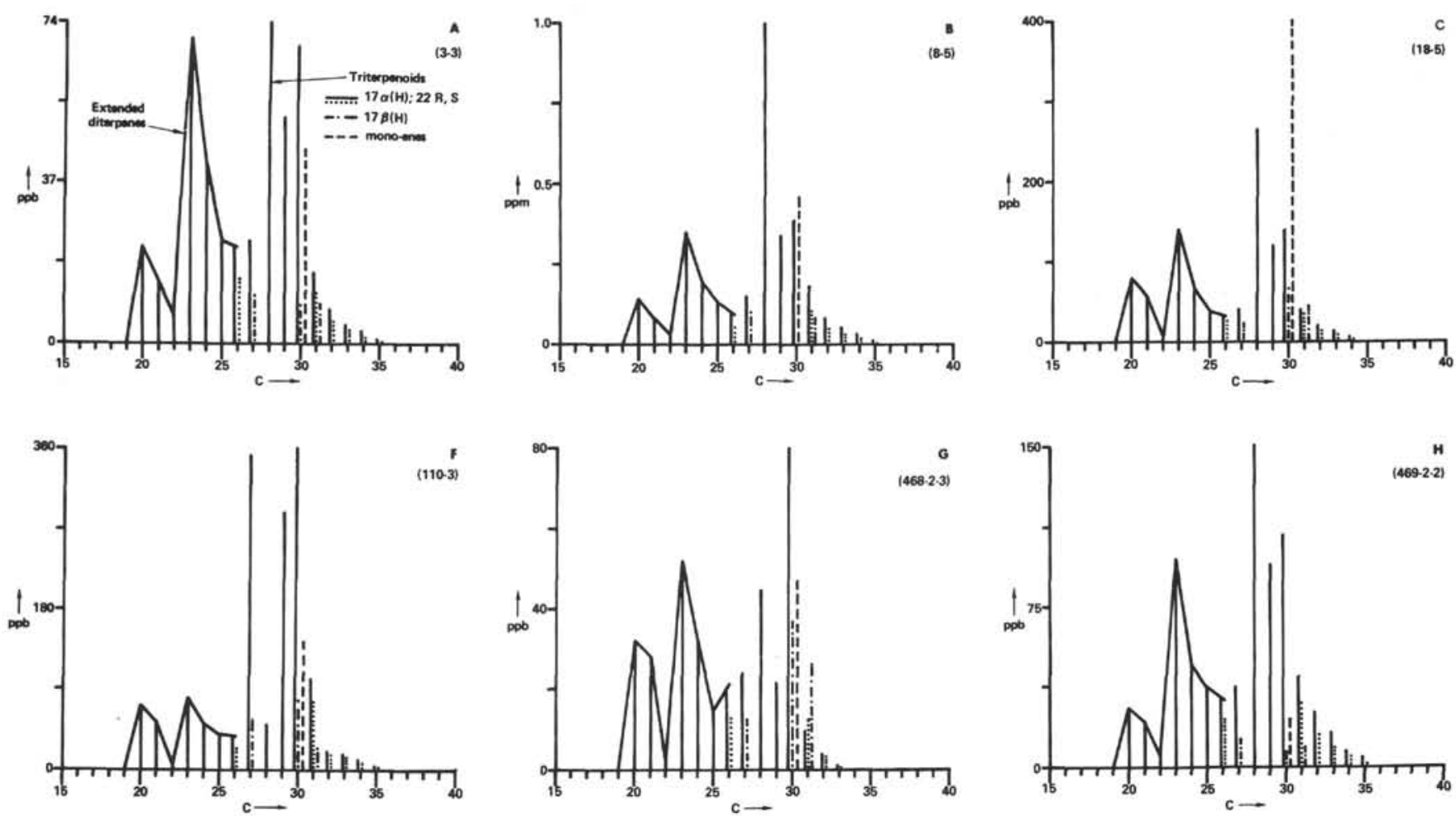

Figure 5. Relative distribution diagrams for extended diterpanes and triterpenoids. (The concentrations are based on the relative intensity of the $\mathrm{m} / \mathrm{z} 191$ mass chromatograms and gas chromatographic response. The R and S diastereomers of the extended homologs are also indicated, and the $\mathrm{C}_{28}$ is $17 \alpha(\mathrm{H}), 18 \alpha(\mathrm{H}), 21 \beta(\mathrm{H})-28,30$-bisnorhopane. A. Sample 467-3-3, 105-120 cm; B. Sample 467-8-5, 100-117 cm; C. Sample 467-18-5, 100-118 cm; D. Sample 467-41-4, 100-121 cm; E. Sample 467-85-4, 105-116 cm; F. Sample 467-110-3, 5-9 cm; G. Sample 468-2-3, 100-120 cm; H. Sample 469-2-2, 136-150 cm; I. Sample BLM 193, 25-31 cm, Southern California Bight [Simoneit and Kaplan, 1980]; and J. Sample 30 G-5, Guaymas Basin [Simoneit et al., 1979].)

ranged from $\mathrm{C}_{31}$ to $\mathrm{C}_{35}$ and were resolved into two diastereomers at the $\mathrm{C}-22$ position. The $22 \mathrm{~S}$ to $22 \mathrm{R}$ ratios were variable and approach unity for some samples, analogous to the samples from the Southern California Bight (Simoneit and Kaplan, 1980; Venkatesan et al., 1980). The $C_{28}$ triterpane was identified from its retention index and mass spectrum (Fig. 6A) as $17 \alpha(\mathrm{H})$, $18 \alpha(\mathrm{H}), 21 \beta(\mathrm{H})-28,30$-bisnorhopane (III; Simoneit and Kaplan, 1980; Seifert et al., 1978). It was present in all samples and was the dominant analog in samples $467-$ $3-3,467-8-5$, and 469-2-2. The similarity of the extended diterpane and triterpane distributions of the shallower samples (467-3-3, 467-8-5, 467-18-5, 468-2-3, and 469-2-2) with some of those of the samples from the Southern California Bight (e.g., Fig. 5I; Simoneit and Kaplan, 1980) lend support to paleoseepage or erosive recycling of more mature bitumen to these sediments. This is further supported by the presence of a broad envelope of unresolved branched and cyclic hydrocarbons in these samples. The triterpenoid distributions of these samples are completely different from the uncontaminated distribution; for example, from the Guaymas Basin in the Gulf of California (Fig. 5J); Simoneit et al., 1979).

Indicators of an additional syngenetic component of triterpenoids were the unsaturated hydrocarbons and acids. Triterpenoid ketones were only trace constituents. The major unsaturated triterpenoid was identified as iso-hop-13(18)-ene (IV) from its retention index and mass spectrum (Fig. 6B) (Ageta et al., 1968). It is the major triterpenoid of Sample 467-18-5 and occurs in excess of hop-17(21)-ene (V) in all the other samples. Isohop-13(18)-ene was not detected in the shallower sediment samples of the Southern California Bight (Simoneit and Kaplan, 1980), where the major unsaturated triterpenes consisted of primarily diploptene and lesser amounts of $17 \beta(\mathrm{H})$-hop-21(22)-ene and hop-17(21)-ene. Diploptene and $17 \beta(\mathrm{H})$-hop-21(22)-ene were not present in these samples. Minor amounts of iso-trisnorhopane (VI) were present in all samples. This compound may represent a degradation product of iso-hop-13(18)-ene. Ageta et al. (1968) reported iso-hop-13(18)-ene present in ferns. Such a source seems unlikely for these samples, especially when considered with the presence of the other major non-hopanoid structures (cf., III, VI, and VII). These compounds are probably derived from microorganisms in the autochthonous environment.

The fatty acid fractions contained varying amounts of extended triterpenoidal acids, and Sections 467-85 $-4,467-110-3$, and 468-18-3 contained no detectable amounts of these cyclic acids. The extended $17 \beta(\mathrm{H})$ hopanoic acids, ranging from $C_{31}$ to $C_{33}$, with $17 \beta(H)$ bishomohopanoic acid as the major homolog, were present in Sections 467-41-4, 468-2-3, 469-2-2, and 46943-1. The predominent stereochemistry was $17 \beta(\mathrm{H})$ with only one diastereomer and traces of the $17 \alpha(\mathrm{H})$ epimers. Samples 467-3-3, 467-8-5, and 467-18-5 contained a series of extended 28-norhopanoic acids, ranging from 

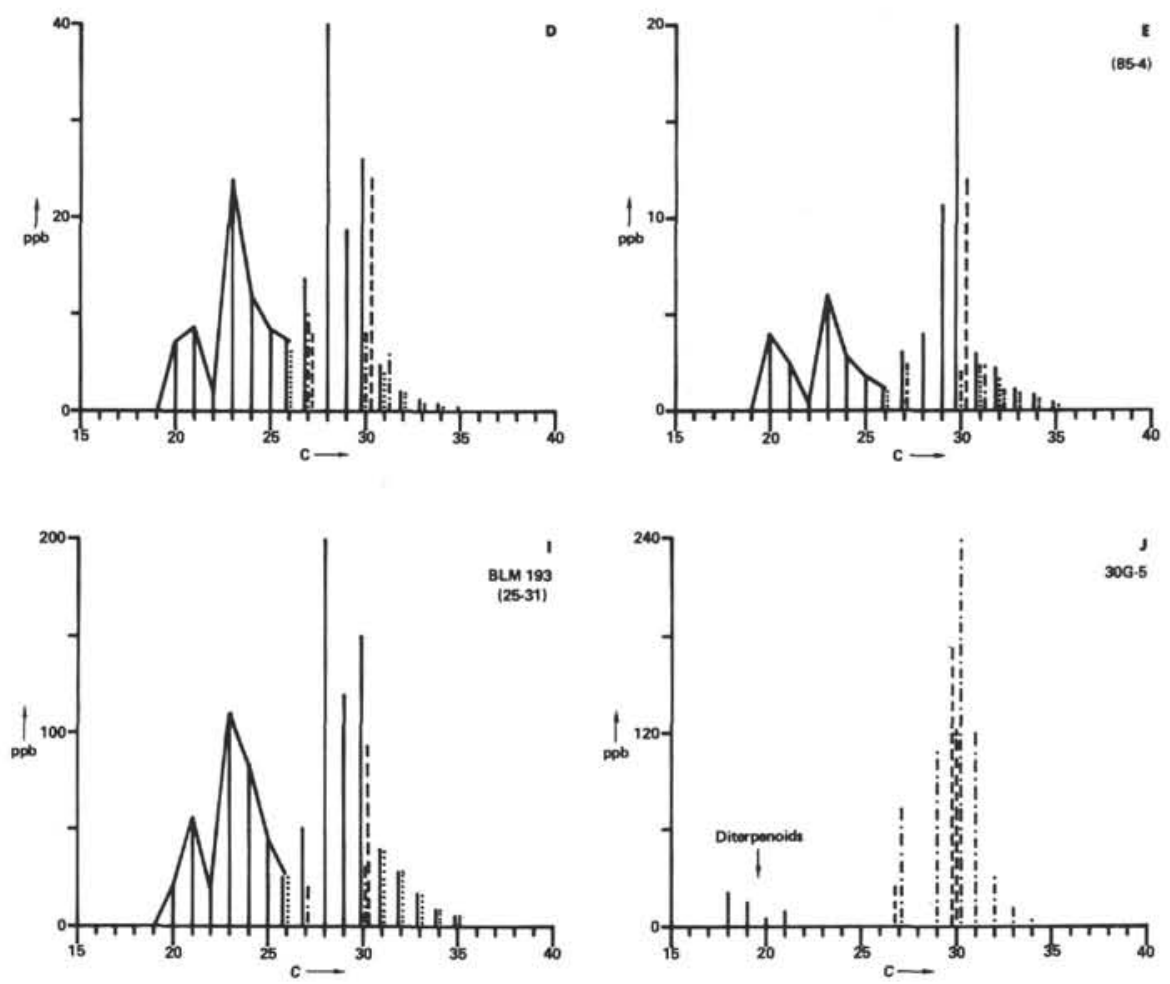

Figure 5. (Continued).

$\mathrm{C}_{30}$ to $\mathrm{C}_{33}$, with the $\mathrm{C}_{31}$ homolog as the major compound. The structure of the $\mathrm{C}_{31}$ homolog was deduced from its mass spectrum (Fig. 6C) to be 28-norbishomohopanoic acid (VII). The biogenic source of these compounds is unknown but may be analogous to that of the other extended hopanoic acids from bacteriohopanepolyols of a microbial origin (Ourisson et al., 1979). The biogenic precursors of the extended 28-norhopanoic acids may also be the source of dominant $17 \alpha(\mathrm{H}), 18 \alpha$ (H),21 $\beta(\mathrm{H})$-28,30-bisnorhopane (III).

The steranes present in these samples consisted primarily of the $5 \alpha(\mathrm{H})$ and $5 \beta(\mathrm{H}), 8 \beta(\mathrm{H}), 14 \alpha(\mathrm{H})$ homologs (VIII, Fig. 7), ranging from $C_{26}$ to $C_{29}$, with lesser amounts of 4-methylsitostane (VIII, $\mathrm{R}^{\prime}=\mathrm{CH}_{3}$ ). Sections 467-3-3, 467-8-5, 467-18-5, 467-41-4, 467-85-4, and 467-110-3 contained varying amounts of norcholestane (IX). Pregnane $\left(\mathrm{C}_{21} \mathrm{H}_{36}\right)$ was also identified in these samples (Fig. 7). The presence of norcholestane may indicate an origin from marine biogenic sources (e.g., Djerassi et al., 1979). The dominance of the $\mathrm{C}_{27}$ sterane in all samples is more characteristic of an origin from marine planktonic detritus (Huang and Meinschein, 1979). However, the high concentrations of the $5 \beta(\mathrm{H})-$ steranes in the shallower sections (e.g., 467-3-3, 467-8-5, and 469-2-2) indicate an admixture of geologically mature bitumen from recycled or paleoseep material ( $\mathrm{Si}$ moneit and Kaplan, 1980). This can be compared with the example of a sample from the Southern California Bight (Fig. 7H). The isomeric $5 \alpha(\mathrm{H})$ or $5 \beta(\mathrm{H}), 8 \beta(\mathrm{H})$, $14 \beta(\mathrm{H})$-steranes $(\mathrm{X})$ were present in most of the samples as the second most abundant steranes and occurred in essentially a 1:1 ratio of diastereomers. The 4-methylsitostane is a further indicator of an autochthonous ma- rine component (Simoneit, 1978). Rearranged steranes and their monoaromatic analogs were present as trace constituents only. Pregnane $\left(\mathrm{C}_{21} \mathrm{H}_{36}\right)$ was detected as a significant component of all samples (Fig. 7), and its source is uncertain. Sterenes and steradienes were not present as significant constituents. Also, the polyolefinic hydrocarbons detected in the shallow Southern California Bight sediments (Simoneit and Kaplan, 1980) were not present in these samples.

Traces of the diterpenoid hydrocarbon derivatives retene, dehydroabietin, simonellite, dehydroabietane, norsimonellite, methylphenanthrene, and cadalene were detected in some samples. Coupled with the presence of low amounts of dehydroabietic acid, these traces indicate a minor influx of resinous higher plant detritus (Simoneit, 1977).

The presence of organic or elemental sulfur has been used as an indicator of anoxic sedimentary conditions (Didyk et al., 1978). With the present GC/MS system, the elemental sulfur could be speciated into some polysulfide moieties. Thus the polysulfide peaks corresponding to $\mathrm{S}_{8}, \mathrm{~S}_{7}$, and $\mathrm{S}_{6}$ are resolved in the GC/MS data (Fig. 8) and their molecular weights confirmed by the mass spectra. Sections 467-3-3, 467-8-5, 467-18-5, 467$41-4,467-110-3$, and 469-2-2 contained these polysulfides, indicating euxinic sedimentary conditions. The other lipid data also lead to this conclusion.

\section{Kerogens}

Kerogen combustion followed by manometric measurement of the resultant gases for a determination of $\mathrm{C}, \mathrm{H}, \mathrm{N}$, and $\mathrm{O}$ in the original kerogen generally has given the elemental results listed in Table 1. Some of the 

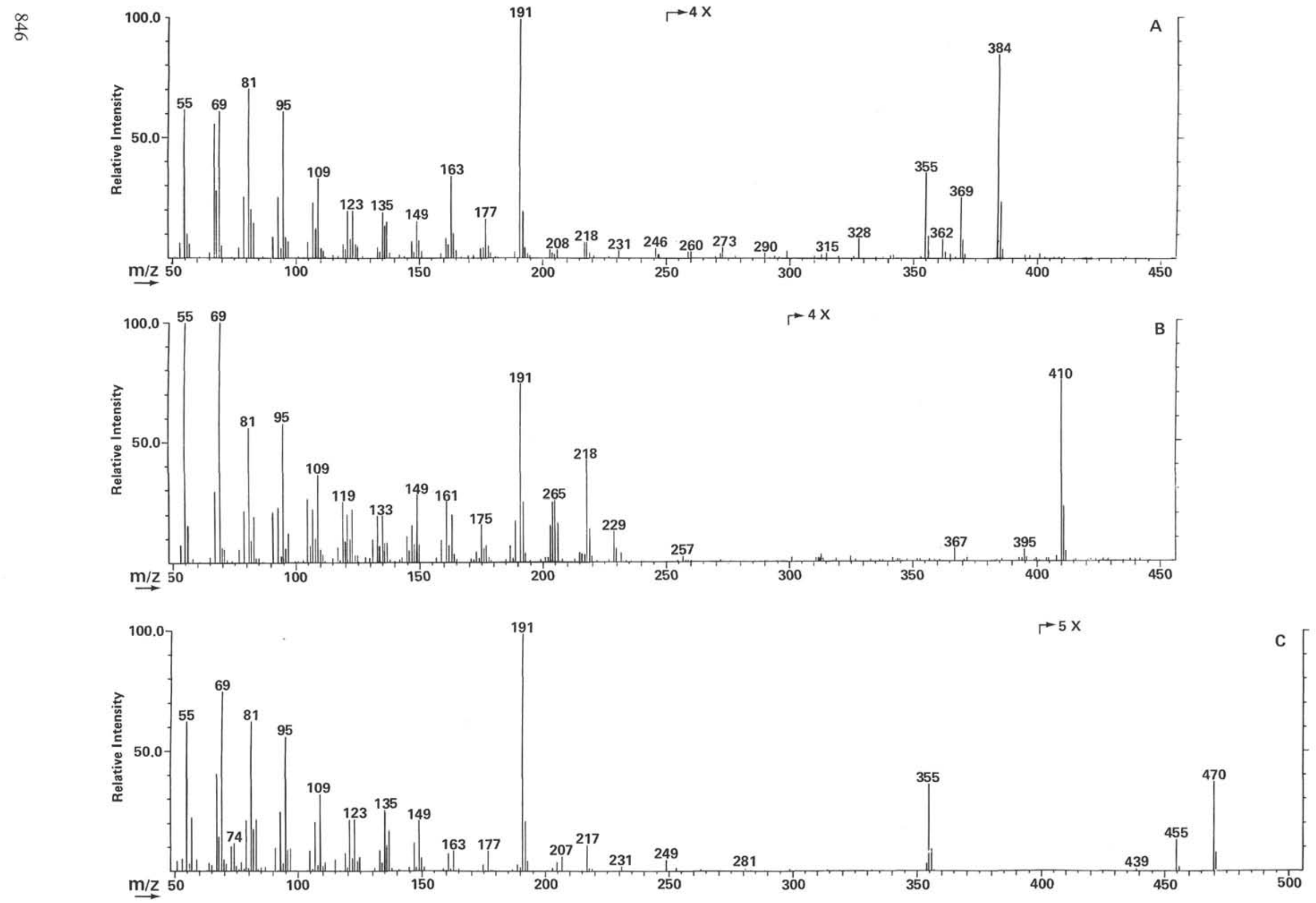

Figure 6. Selected mass spectra of molecular markers in lipids of Sample 467-18-5, 100-118cm. A. 17 $\alpha(\mathrm{H}), 18 \alpha(\mathrm{H}), 21 \beta(\mathrm{H})-28,30$-bisnorhopane (III); B. iso-hop-13(18)-ene (IV); and C. 28-norbishomohopanoic acid (as methyl ester) (VII). 

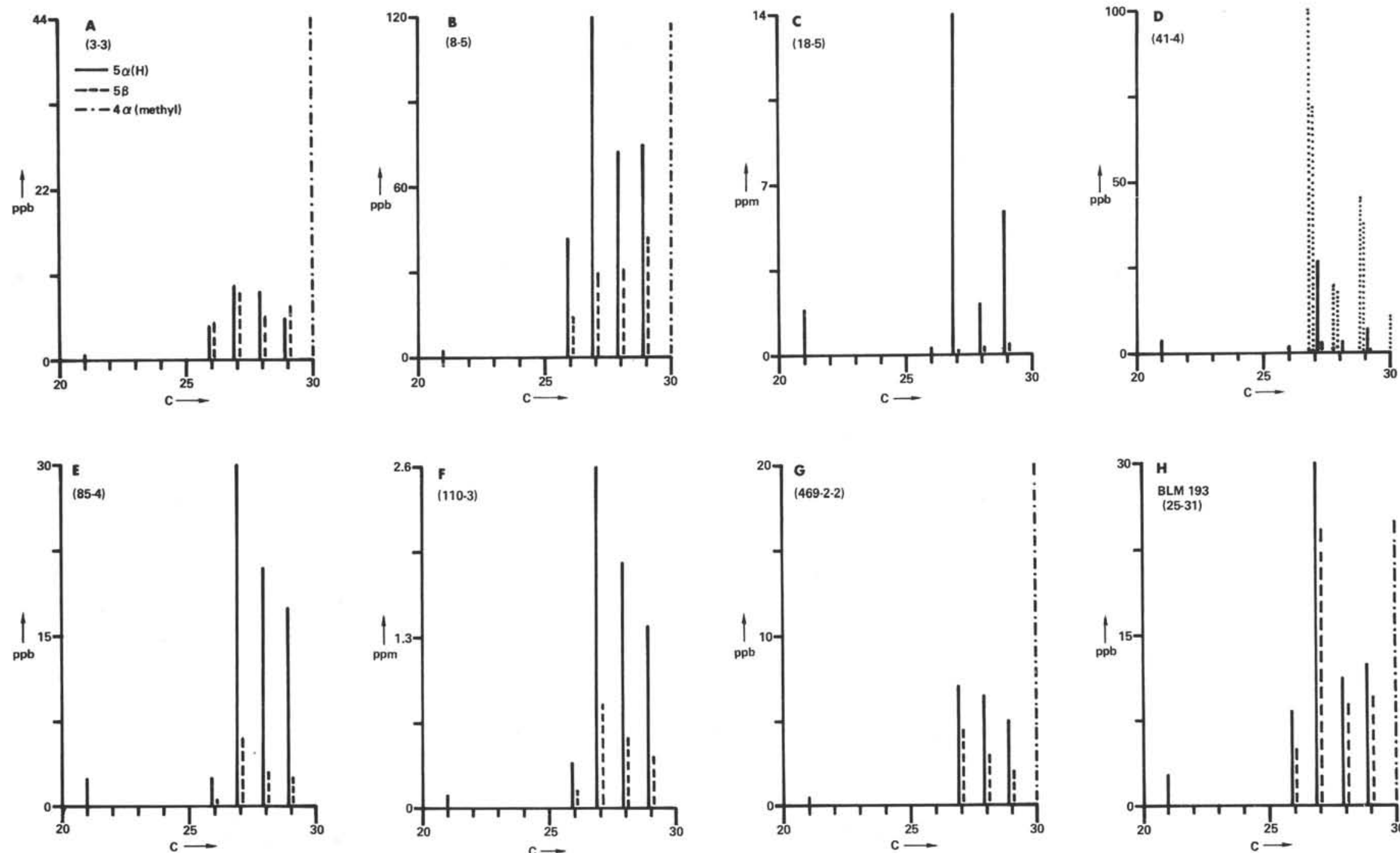

Figure 7. Distribution diagrams for steranes (see legend in A.) and also sterenes (indicated by ...) of the samples from Sites 467 to 469 . A. Sample 467-3-3, 105-120 cm; B. Sample 467-8-5, 100-117 cm; C. Sample 467-18-5, 100-118 cm; D. Sample 467-41-4, 100-121 cm; E. Sample 467-85-4, 105-116 cm; F. Sample 467-110-3, 5-9 cm; G. Sample 469-2-2, 136-150 cm; and H. Sample BLM 193, 25-31 cm, Southern California Bight [Simoneit and Kaplan, 1980].) 


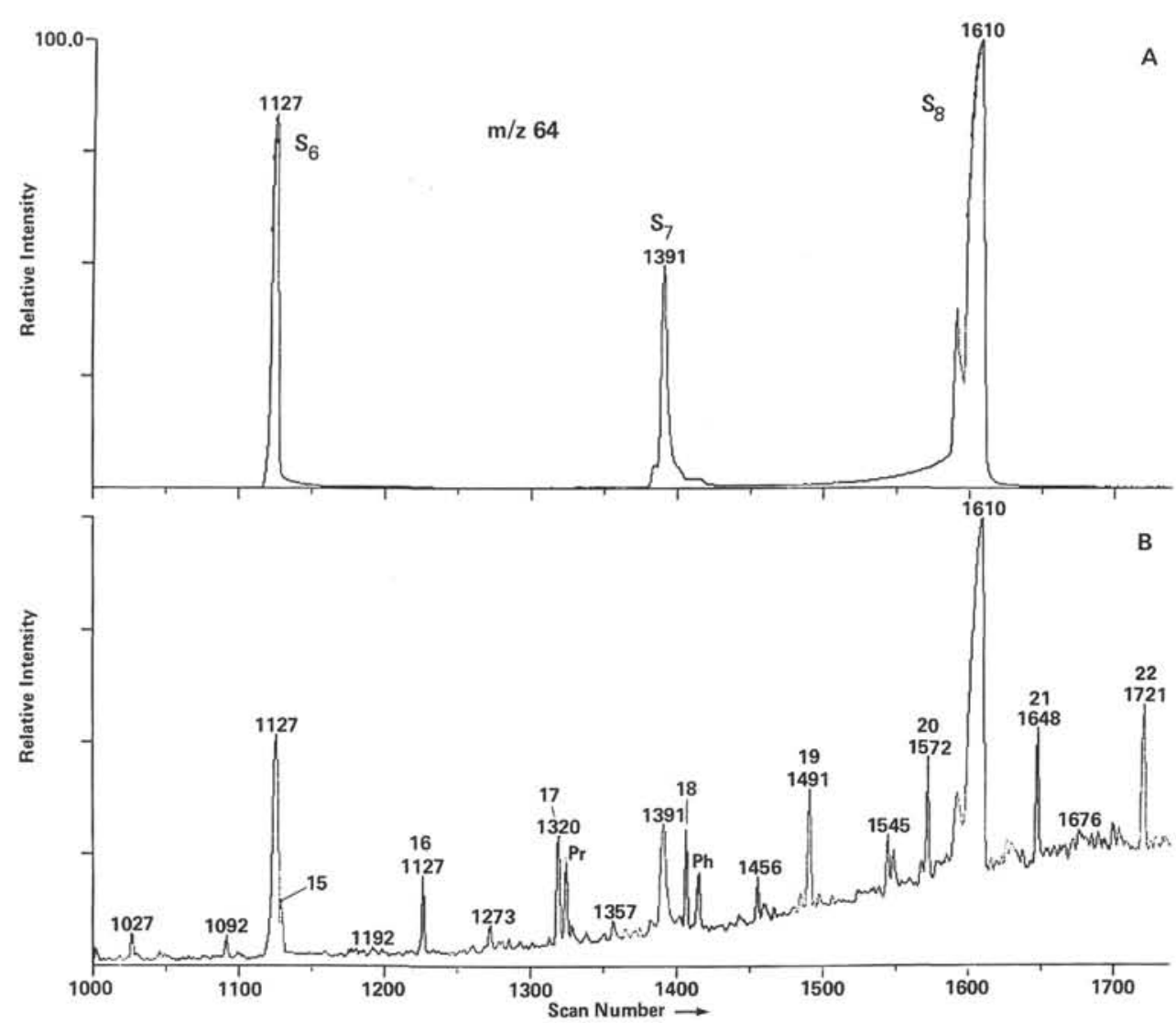

Figure 8. GC/MS data for the polysulfides. (A. Mass chromatogram for $\mathrm{m} / \mathrm{z} 64$, the base peak of $\mathrm{S}_{6}, \mathrm{~S}_{7}$, and $\mathrm{S}_{8}$. B. Total ion current trace.)

variability can be attributed to the high ash content in all but one of the kerogen samples (No. 7-Hole 468). Cores from Holes 467 and 469 contained variable amounts of pyrite $\left(\mathrm{FeS}_{2}\right)$, which was also detected in the initial core analyses on board ship, thus high ash values in the kerogen are not surprising. The $\mathrm{H} / \mathrm{C}$ values for Samples 5 and 9 are therefore high. Values for Samples $1,3,4,6$, and 8 fall in the more aromatic range, whereas Samples 2, 5, 7, and 9 are more aliphatic (cf., Table 1).

The $\delta^{13} \mathrm{C}, \delta^{15} \mathrm{~N}$, and $\delta \mathrm{D}$ data for the kerogens are listed in Table 1. Values for $\delta^{13} \mathrm{C}$ fall within the range of -20 to $-23 \%$ and are indicative of chiefly marine planktonic source material with minor input of terrestrial higher plant detritus (Sackett, 1964; Peters et al., 1978; Stuermer et al., 1978).

In addition to source elucidation, $\delta^{13} \mathrm{C}$ data have been used to indicate structural modification of kerogen resulting from microbial breakdown or from elevated thermocatalytic effects due to increased burial. Figure 9 shows a plot of kerogen $\delta^{13} \mathrm{C}$ versus depth within each core. In Hole 467, shallow samples become isotopically heavier with depth, reaching a maximum value at 381 meters sub-bottom (Sample 4), and then decreasing to the lowest $\delta^{13} \mathrm{C}$ value in the core at the concomitant greatest sub-bottom depth of 1035 meters (Sample 6). This $\delta^{13} \mathrm{C}$ profile may be the result of two competing processes: the microbial or oxidative alteration of kerogen substrate moieties enriched in ${ }^{12} \mathrm{C}$, and the inorganic thermal decomposition of kerogen carboxyl functionali- ties that are enriched in ${ }^{13} \mathrm{C}$. It is well established that less energy is required to break ${ }^{12} \mathrm{C}-{ }^{12} \mathrm{C}$ bonds than it is for ${ }^{13} \mathrm{C}-{ }^{12} \mathrm{C}$ linkages (Stevenson et al., 1948; Brodskii et al., 1959); therefore degradation of kerogen would be expected to utilize preferentially ${ }^{12} \mathrm{C}-{ }^{12} \mathrm{C}$ fractions, leaving the residual kerogen heavier in ${ }^{13} \mathrm{C} /{ }^{12} \mathrm{C}$. Indeed, this appears to be the dominant process for Hole 467 until, at a sub-bottom depth of 381 meters (4), there is a reversal and $\delta^{13} \mathrm{C}$ becomes increasingly lighter. That phenomenon may be attributed to the overriding effects of thermal decomposition of kerogen portions that are ${ }^{13} \mathrm{C}$ enriched in conjunction with the waning fractionation of ${ }^{12} \mathrm{C}$-rich groups from the microbial or oxidative degradation of kerogen. Slight systematic enrichment in ${ }^{12} \mathrm{C}$ in the residual kerogen, which is derived from the elimination of $-\mathrm{COOH}$ groups heavy in ${ }^{13} \mathrm{C}$, has previously been demonstrated (Abelson and Hoering, 1961; Galimov, 1973, 1978; Rohrback, 1979). It is not clear that the pumiceous tuff located in the sedimentary column between 700 and 820 meters might have accelerated the rate of decarboxylation reactions in the kerogen, because there are no major discontinuities in the decreasing $\delta^{13} \mathrm{C}$ trend with depth for the data points at 381 meters (4), 800 meters (5), and at 1035 meters (6). More information is needed on samples taken within close proximity both above and below the tuff interval in order to clarify the situation. Similarly, Hole 468 shows an increase in $\delta^{13} \mathrm{C}$ from a depth of 7.5 meters (7) to the deepest subsample recovered at 160 meters (8). Appar- 


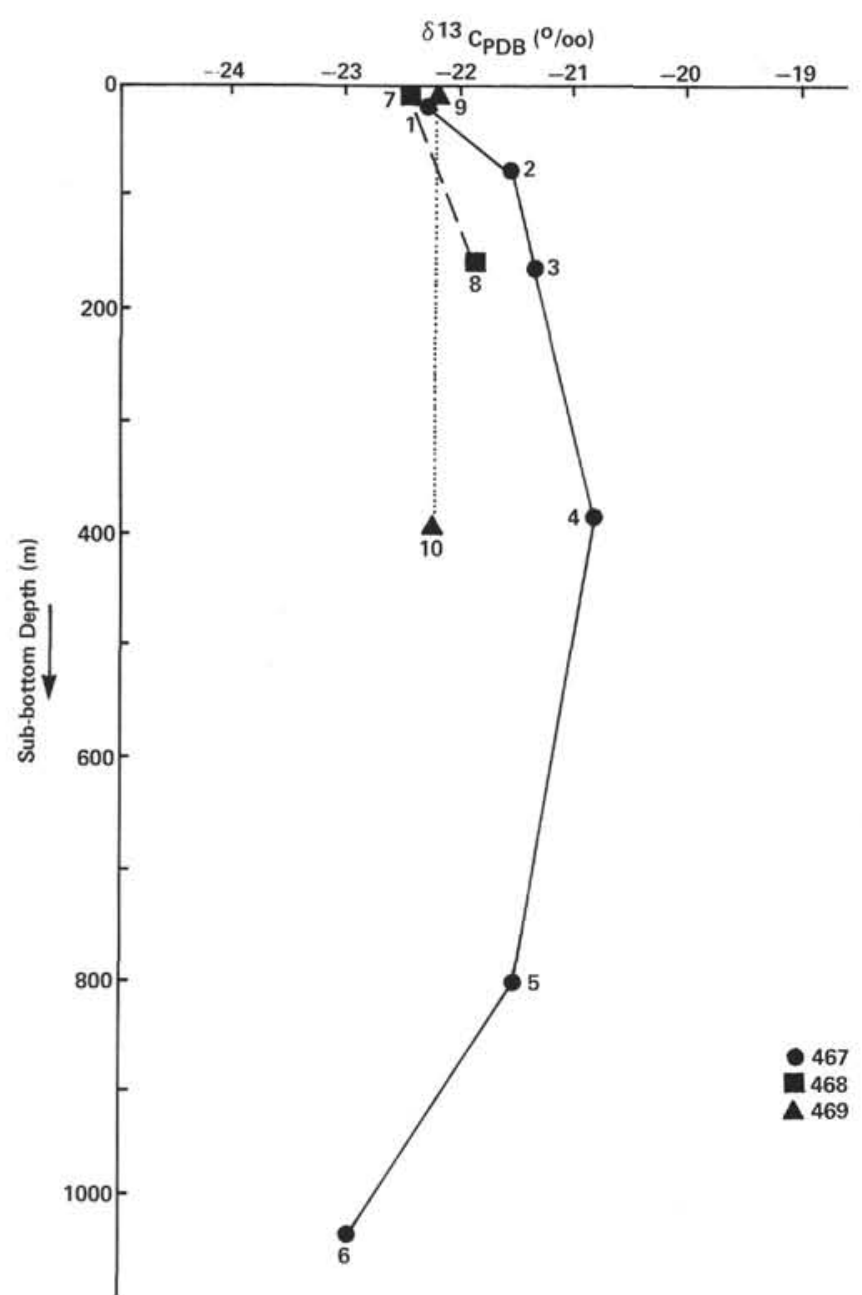

Figure 9. Plot of the $\delta^{13} \mathrm{C}$ data versus depth for the kerogens from Sites 467 to 469 .

ently, temperature effects were not great enough to initiate decarboxylation of kerogen, and decomposition by microbes or oxidation was the dominant process, yielding kerogen residues heavier in $\delta^{13} \mathrm{C}$. Conversely, Hole 469 shows nearly a constant $\delta^{13} \mathrm{C}$ value with depth $(-22.20 \%$ o), which could mean that microbial-oxidative and thermal decomposition processes for the refractory organic material were roughly in balance with one another throughout the core intervals sampled. Because of the limited data, however, this should be interpreted with caution until additional $\delta^{13} \mathrm{C}$ analyses can be conducted on further samples taken between Samples 9 and 10.

Deuterium ratios for the ten kerogen samples demonstrate greater variance, showing a distribution between -140 to $+29 \%$. Before an assignment of organic source material can be made on the basis of $\delta \mathrm{D}$ variance, limitations to the usage of the deuterium ratio must be understood. Generally, $\delta \mathrm{D}$ results are thought to provide a less concrete basis for the elucidation of organic source material, because deuterium values have previously been shown to be intrinsically related to the $\delta \mathrm{D}$ ratios of meteoric waters that drain into a given geographic location, rather than to inherent biological fractionation processes of marine and terrestrial biota (Hoering, 1975). Nissenbaum (1974), however, detected slight differences among $\delta \mathrm{D}$ measurements of various marine and terrestrial humic acids and found that for a given restricted geographic location $\delta \mathrm{D}$ ratios ranged from -102 to $-110 \%$ o for humic material in the underlying recent marine sediments. Nissenbaum attributed this range to contributions primarily by marine plankton. Comparing this $\delta \mathrm{D}$ range to the $\delta \mathrm{D}$ values of these kerogen samples (Table 1), only Samples 1 and 8 (Quaternary and lower/middle Miocene, respectively) coincide with the -102 to $-110 \%$ interval. Clearly, the $\delta \mathrm{D}$ values generated in this study do not support the corresponding ${ }^{13} \mathrm{C}$ data, which irrevocably point to a marine planktonic origin for these kerogens. Factors that may have induced the wide variations in $\delta \mathrm{D}$ measured in the other eight sample intervals include the following:

1) presence of heavy minerals in the isolated kerogen fractions could either increase or diminish $\delta \mathrm{D}$ during the separation and pyrolysis phases of kerogen analysis (Durand and Monin, 1978),

2) fractionation due to equilibration or exchange of kerogen hydrogen during analytical procedures (Hoering, 1975),

3) fractionation of the hydrogen fraction contained in humates during diagenetic processes that lead to kerogen formation; thus -102 to $-110 \%$ omeasured in humates is fundamentally not applicable to kerogen, and

4) Application of varying degrees of thermal stress to the kerogen after burial within the sediment.

Knowledge of the thermal stress within a given sediment may be used to demonstrate the changes in $\delta \mathrm{D}$ with depth and thus to correlate increasing temperature due to burial within a geothermal gradient. It may therefore be possible to document paleothermal events by analysis of anomalous $\delta \mathrm{D}$ fluctuations with depth (Fig. 10). For Hole $467, \delta D$ remains nearly constant to a depth of 381 meters (4), then increases to a maximum value at 800 meters (5), and finally decreases in the deepest kerogen sample. The substantial depletion of ${ }^{12} \mathrm{C}$ at a depth of 800 meters also coincides with the appearance of a pumiceous tuff. It seems evident that the heat from this nearly cooled volcanic material was sufficient enough to cause mass fractionation of the lighter isotope, leaving behind a deuterium-enriched kerogen residue. Moreover, in terms of $\mathrm{D} / \mathrm{H}$ content, the sample at 800 meters (5) is diagenetically more mature than the lower kerogen sample from 1035 meters (6). This anomalous maturation in the tuff vicinity may be interpreted as a Rayleigh distillation effect in which the lighter isotope is distilled off first, the magnitude of which is related to the absolute distance from the heat source. A similar phenomenon has been observed in the thermal alteration of Cretaceous black shale by basaltic intrusions in the eastern Atlantic (Simoneit et al., 1978).

For Site $468, \delta \mathrm{D}$ increases with depth, however, the deepest sample is only 160 meters (8). Apparently, the sediment in this interval of 7.5 to 160 meters did not undergo an unusual thermal stress, because the $\delta \mathrm{D}$ lies 


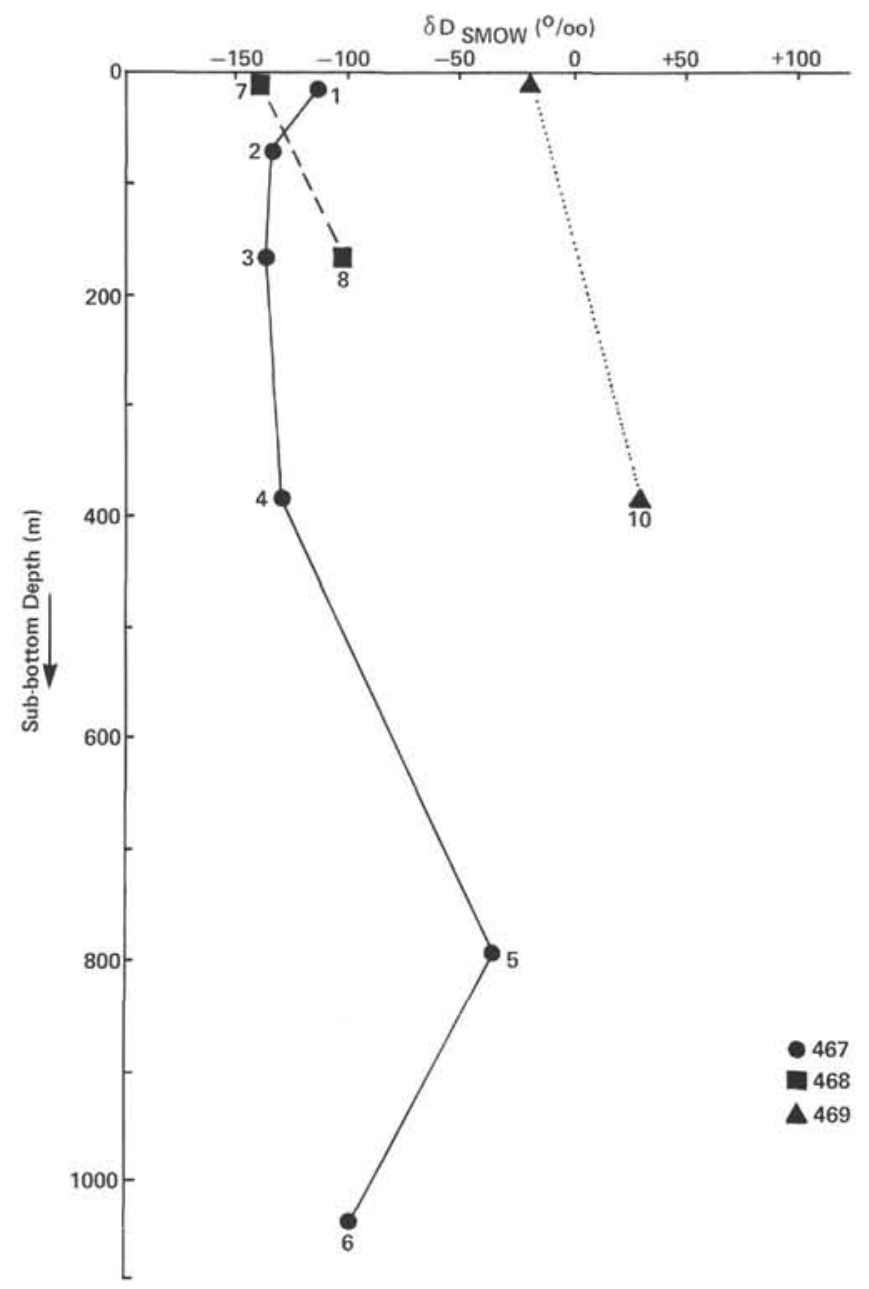

Figure 10. Plot of the $\delta \mathrm{D}$ data versus depth for the kerogens from Sites 467 to 469 .

within the same range as for the shallow kerogen at Site 467 , despite the fact that volcanic ash layers appear in the core lithology at a depth of about 230 meters. Similar behavior is not true for Hole 469 , in which $\delta \mathrm{D}$ is enriched by 40 to $70 \%$ in the core relative to the $\delta \mathrm{D}$ values in either Hole 467 or 468 . The organic matter in Hole 469 exhibits a high diagenetic maturity in terms of very large $\mathrm{D} / \mathrm{H}$ ratios, which may well have been induced by the high thermal stress imparted by the observed diabase intrusion. Moreover, the intrusion appears to be upper Quaternary; this would account for the high $\delta \mathrm{D}$ value in the shallow 10.0-meter (9) sample that was formed during this era. Therefore, when comparing the relative thermal stress induced by volcanic debris or alternatively, the greatest extent of diagenetic maturity of the organic matter, the following is true: the core from Hole 469 shows extensive thermal degradation, followed by localized zones of moderately heated kerogen from Hole 467, and finally, no significant thermal alteration of kerogen from Hole 468.

When a correlation is made between $\delta \mathrm{D}$ and $\delta^{13} \mathrm{C}$ for each kerogen sample (Fig. 11), a compelling segregation of Holes 467 and 468 from 469 is evident. This separation of data points may be a manifestation of differen-

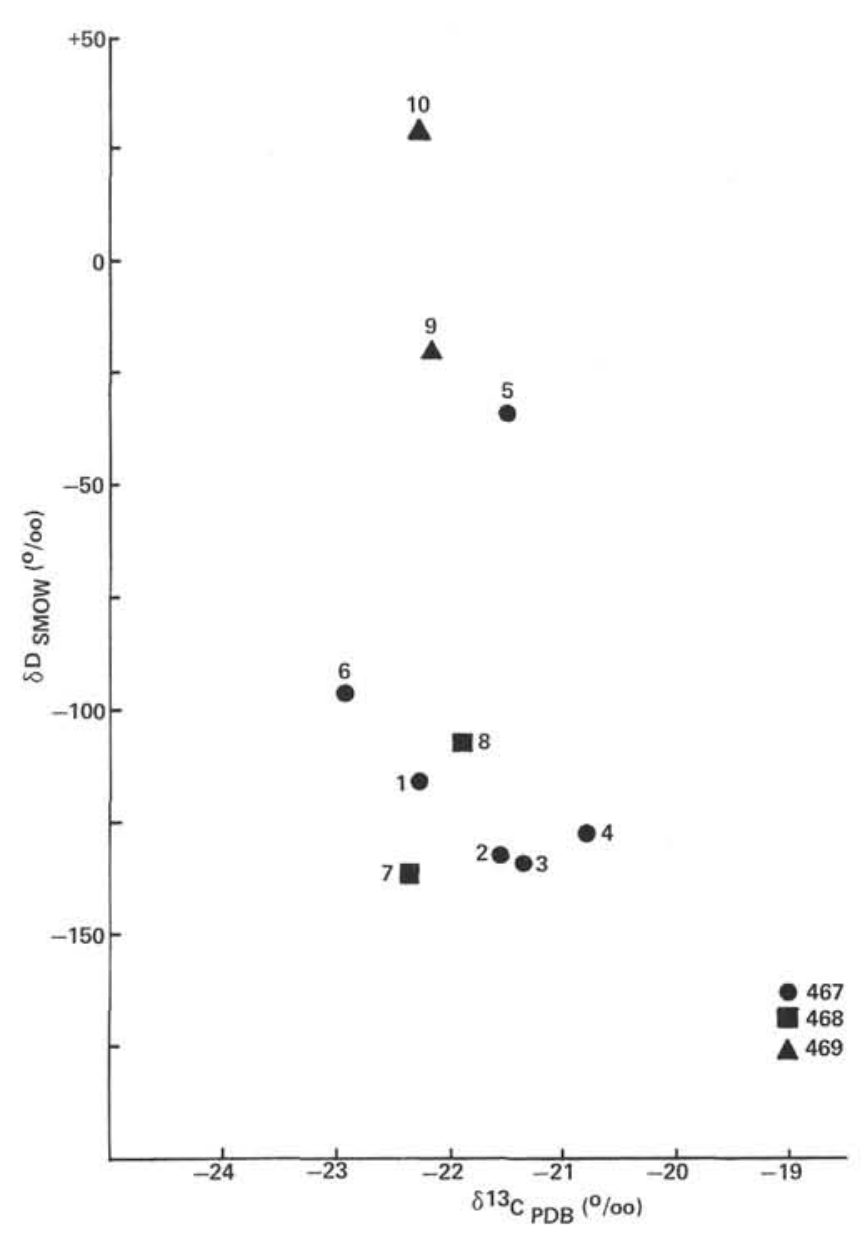

Figure 11. Correlation diagram of $\delta \mathrm{D}$ versus $\delta^{13} \mathrm{C}$ for the kerogens from Sites 467 to 469 .

tial thermal stress on the various kerogen fractions by a nonuniform thermal gradient or by nonhomogeneous heating by volcanic debris. That is assuming that the effects of experimental fractionation, heavy mineral interaction, meteoric deuterium values, and organic source material are roughly equivalent among all ten kerogen samples. Overall, $\delta^{13} \mathrm{C}$ shows minor deviation $(-20$ to $-23 \% 0$ ), whereas $\delta \mathrm{D}$ values demonstrate significant variability $(-140$ to $+29 \%$ ). By plotting the changes in $\delta \mathrm{D}$ and $\delta^{13} \mathrm{C}$ among kerogen samples from a single drill site, consistent progressions become apparent. At Hole 467 , shallow samples are clustered together (1 to 4 ) having low $\delta \mathrm{D}$ ratios. Deeper samples (5 and 6$)$ show an enrichment in deuterium of about $40 \%$, relative to the shallow kerogen. Carbon values are more or less in the same range for all analyzed kerogen, with a variability of approximately $2 \%$. Thus with depth there is a rapid increase of $\delta \mathrm{D}$ relative to $\delta^{13} \mathrm{C}$, and this relation may indicate the accelerated effect of biological and abiological kerogen alteration processes acting upon the lighter element. This same trend is noted for Hole 469 and is less pronounced for Hole 468. Consequently, in diagenetic alteration of kerogen, changes of greater magnitude occur for hydrogen components than for carbon components. This generalization is supported by simulated laboratory thermal alterations of kerogens (Bae- 
decker et al., 1977; Ishiwatari et al., 1977; Sackett, 1978; Rohrback, 1979; Durand and Monin, 1978), which show the degree of elemental loss in the order of $\mathrm{O}>\mathrm{H}>\mathrm{N}>\mathrm{C}$.

The $\delta^{15} \mathrm{~N}$ data for the kerogens are also listed in Table 1 , and they range from +1.4 to $+11.8 \%$, with considerable scatter and error due to the low levels of nitrogen contents. The correlation of $\delta^{15} \mathrm{~N}$ versus $\delta^{13} \mathrm{C}$ is shown in Fig. 12, and the correlation line (slope $=1.1$ ) for organic matter from the continental shelf sediments of the northeast Pacific (Peters et al., 1978) is also indicated. The interpretation of the data is limited, but it shows that all these kerogens are of a mixed composition derived from terrestrial and marine detritus. Based on the $\delta^{15} \mathrm{~N}$ values, the samples from Site 469 are distinctly more marine in character.

\section{CONCLUSIONS}

The nature and composition of the lipids and kerogens of selected core samples from Sites 467 to 469 were determined; these data enabled us to evaluate the genetic origin and maturity of that organic matter.

\section{Lipids}

The lipids had a multiple origin from primary autochthonous marine production (i.e., microbial residues) and from allochthonous sources (Table 3). The allochthonous influx was composed of terrigenous detritus, primarily higher plant wax and traces of resin residues, and geologically mature bitumen from seepage or from recycled older sedimentary material. These inferences are based on the homolog distributions of the $n$-alkanes and $n$-fatty acids, with the shape and magnitude of the unresolved branched and cyclic hydrocarbons (the hump), and the structural and stereochemical compositions of the molecular indicators.

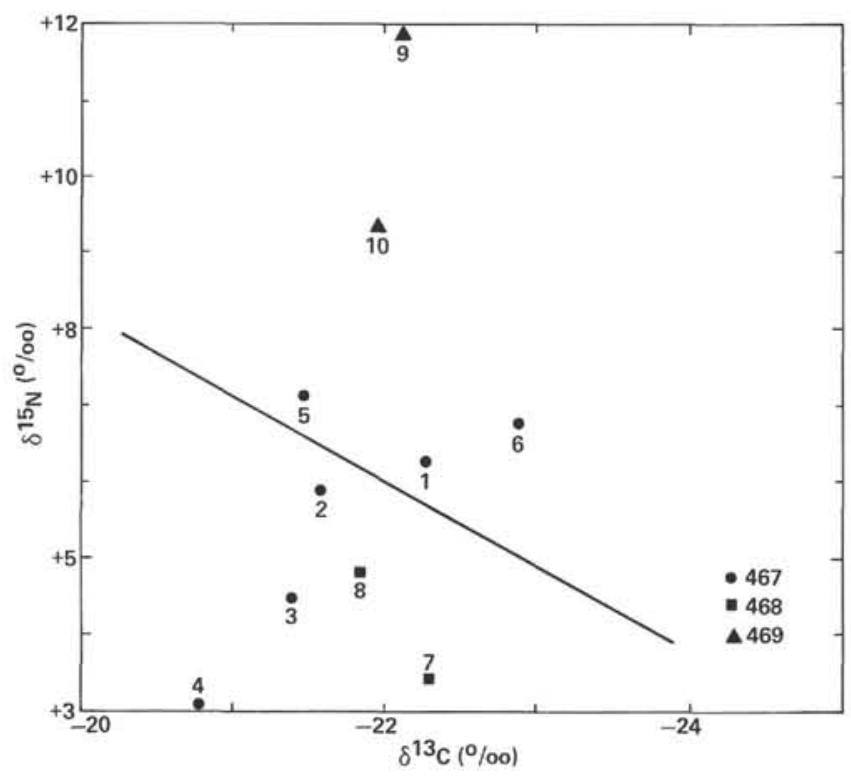

Figure 12. Correlation diagram of $\delta^{15} \mathrm{~N}$ versus $\delta^{13} \mathrm{C}$ for the kerogens from Sites 467 to 469 .
Table 3. Inferred sources of lipids and kerogen of Leg 63 samples based on organic geochemical data.

\begin{tabular}{|c|c|c|}
\hline Section & Lipids & Kerogen \\
\hline $467-3-3$ & marine/terrigenous ${ }^{\mathrm{a}}$ & marine \\
\hline $8-5$ & $\overline{\text { marine/terrigenous }}$ & marine \\
\hline $18-5$ & marine/terrigenous & marine/terrigenous ${ }^{\mathrm{a}}$ \\
\hline $41-4$ & marine/terrigenous & $\overline{\text { marine }}$ \\
\hline $85-4$ & $\overline{\text { marine }}$ & marine \\
\hline $110-3$ & marine/terrigenous & marine \\
\hline $468-2-3$ & $\overline{\text { marine }} /$ terrigenous & marine \\
\hline $18-3$ & $\overline{\text { marine }}$ & marine \\
\hline $469-2-2$ & marine/terrigenous & marine/terrigenous \\
\hline $43-1$ & marine/terrigenous & marine \\
\hline
\end{tabular}

a Dominant source of two is underscored.

The $\mathrm{Pr} / \mathrm{Ph}$ values ranged from 0.7 to 2.0 and perylene and polysulfide sulfur were present in most samples, indicating partial euxinic paleoenvironmental conditions of sedimentation.

\section{Kerogen}

The $\delta \mathrm{D}$ and $\delta^{13} \mathrm{C}$ values of the kerogen samples demonstrate that Sites 467 to 469 contain organic material principally derived from marine planktonic sources, with a minor input of terrestrial higher plant components (Table 3). Although these sites are within close proximity to each other, the respective sediments show varying degrees of thermal stress (on the basis of the variation of $\delta \mathrm{D}$ with depth). Hole 469 shows anomalously high $\delta \mathrm{D}$ values, which support the idea of localized heating by a recent (Quaternary) diabase intrusion. Alternatively, Site 467 material was moderately heated within close proximity of a vitric tuff, whereas Hole 468 does not show any significant alteration of kerogen by a far-removed lapili tuff. Moreover, the in situ thermal alteration of the organic matter shows these overall trends:

1) $\delta \mathrm{D}$ increases with increasing depth in a normal diagenetic sequence as a result of the preferential loss of the lighter isotope with increasing temperature (mass fractionation).

2) ${ }^{13} \mathrm{C}$ increases with increasing depth, initially, because of microbial degradation, and then decreases with depth due to inorganic breakdown (thermal stress).

3) Loss of $\mathrm{H}$ is more rapid than loss of $\mathrm{C}$ during the normal diagenetic sequence of events.

\section{ACKNOWLEDGMENTS}

We thank D. Winter for stable isotope data and for assistance in sample preparation for stable isotope analyses, E. Ruth for GC/MS data acquisition, and Robert E. Cox and M. I. Venkatesan for manuscript review. Partial financial assistance from the Department of Energy and Bureau of Land Management (Contract Number EY-76-S-03-0034, P.A. 134) is gratefully acknowledged. This paper is Contribution No. 2093, Institute of Geophysics and Planetary Physics, University of California at Los Angeles.

\section{REFERENCES}

Abelson, P. H., and Hoering, T. C., 1961. Carbon isotope fractionation in formation of amino acids by photosynthetic organisms. Proc. Nat. Acad. Sci. U.S.A., 47:623-632. 
Ageta, H., Shioima, K., and Arai, Y., 1968. Fern constituents: neohopane, hopene-II, neohopadiene and fernadiene isolated from Adiantum species. Chem. Commun., 1968:1105-1107.

Baedecker, M. J., Ikan, R., Ishiwatari, R., et al., 1977. Thermal alteration experiments on organic matter in recent marine sediments as a model for petroleum genesis. In Yen, T. F. (Ed.), Chemistry of Marine Sediments: Ann Arbor, Mich. (Ann Arbor Science), pp. 55-72.

Brodskii, A. M., Kalinenko, R. A., and Lavroskii, K. P., 1959. On the kinetic isotope effect in cracking. Int. J. Appl. Radiat. Isot., $7: 118$.

Craig, H., 1957. Isotopic standards for carbon and oxygen and correction factors for mass-spectrometric analysis of carbon dioxide. Geochim. Cosmochim. Acta, 12:133-149.

Didyk, B. M., Simoneit, B. R. T., Brassell, S. C., et al., 1978. Organic geochemical indicators of paleoenvironmental conditions of sedimentation. Nature, 272:216-222.

Djerassi, C., Theobald, N., Kokke, W. ¿.., et al., 1979. Recent progress in the marine sterol field. Pure Appl. Chem., 51:1815-1828.

Durand, B., and Monin, J. C., 1978. Elemental analysis of kerogens. In Durand, B. (Ed.), Kerogen-Insoluble Organic Matter From Sedimentary Rocks: Paris (Editions Technip), pp. 113-142.

Galimov, E. M., 1978, ${ }^{13} \mathrm{C} /{ }^{12} \mathrm{C}$ ratios in kerogen. In Durand, B. (Ed.), Kerogen-Insoluble Organic Matter from Sedimentary Rocks: Paris (Editions Technip), pp. 271-299.

1973. Carbon isotopes in oil and gas geology. Washington (NASA TT F-682)

Haq, B., Yeats, R. S., Barron, J. A., et al., 1979. Eastern Pacific Boundary Currents. Geotimes, 24(4):30-31.

Hoering, T. C., 1975. The biogeochemistry of the stable hydrogen isotopes. Annual Report of the Director, Geophysical Laboratory, Carnegie Inst. Washington Publ. 1974-1975, (Vol. 1975):598-604.

Huang, W.-Y., and Meinschein, W. G., 1979. Sterols as ecological indicators. Geochim. Cosmochim. Acta, 43:739-745.

Ishiwatari, R., Ishiwatari, M., Rohrback, B. G., et al., 1977. Thermal alteration experiments on organic matter from recent marine sediments in relation to petroleum genesis. Geochim. Cosmochim. Acta, 41:815-828.

Nissenbaum, A., 1974. The organic geochemistry of marine and terrestrial humic substances: implications of carbon and hydrogen isotope studies. In Tissot, B., and Bienner, F. (Eds.), Advances in Organic Geochemistry 1973: Paris (Editions Technip), pp. 39-52.

Ourisson, G., Albrecht, P., and Rohmer, M., 1979. The hopanoids. Paleochemistry and biochemistry of a group of natural products. Pure Appl. Chem., 51:709-729.

Peters, K. E., Sweeney, R. E., and Kaplan, I. R., 1978. Correlation of carbon and nitrogen stable isotope ratios in sedimentary organic matter. Limnol. Oceanogr., 23:598-604.

Rohrback, B. G., 1979. Analysis of low molecular weight products generated by thermal decomposition of organic matter in recent sedimentary environments [Ph.D. thesis]. University of California, Los Angeles.

Sackett, W. M., 1964. The depositional history and isotopic organic carbon composition of marine sediments. Mar. Geol., 2:173-185. 19.78. Carbon and hydrogen isotope effects during the thermo-catalytic production of hydrocarbons in laboratory simulation experiments. Geochim. Cosmochim. Acta, 42:571-580.

Seifert, W. K., Moldowan, J. M., Smith, G. W., et al., 1978. First proof of structure of a $\mathrm{C}_{28}$-pentacyclic triterpane in petroleum. Nature, 271:436-437.

Simoneit, B. R. T., 1975. Sources of organic matter in oceanic sediments [Ph.D. dissert.]. University of Bristol, England.

1977. Diterpenoid compounds and other lipids in deep-sea sediments and their geochemical significance. Geochim. Cosmochim. Acta, 41:463-476.

1978. The organic chemistry of marine sediments. In Riley, J. P., Chester, R. (Eds.), Chemical Oceanography (Vol. 7): New York (Academic Press), 233-311.

,1979a. Lipid geochemistry of Cretaceous black shales from the Bay of Biscay, Site 402, and of Eocene mudstone from the Rockall Plateau, Site 404. In Montadert, L., Roberts, D. G., et al., Init. Repts. DSDP, 48: Washington (U.S. Govt. Printing Office), 935-941.

$1979 b$. Organic geochemistry of the shales from the northwestern Proto-Atlantic, DSDP Leg 43. In Tucholke, B. E., Vogt, P. R., et al., Init. Repts. DSDP, 43: Washington (U.S. Govt. Printing Office), 643-649.

1980. Organic geochemistry of Mesozoic sediments from Deep Sea Drilling Project Site 330, Falkland Plateau. In Lancelot, Y., Winterer, E. L., et al., Init. Repts. DSDP, 50: Washington (U.S. Govt. Printing Office), 637-642.

Simoneit, B. R. T., Brenner, S., Peters, K., et al., 1978. Thermal alteration of Cretaceous black shale by basaltic intrusions in the Eastern Atlantic. Nature, 273:501-504.

Simoneit, B. R. T., and Kaplan, I. R., 1980. Triterpenoids as molecular indicators of paleoseepage in Recent sediments of the Southern California Bight. Mar. Environ. Res., 3:113-128.

Simoneit, B. R. T., Mazurek, M. A., Brenner, S., et al., 1979. Organic geochemistry of recent sediments from Guaymas Basin, Gulf of California. Deep-Sea Res., 26A:879-891.

Stevenson, D. P., Wagner, C. D., Beeck, O., et al., 1948. Isotope effect in thermal cracking of propane-1- $\mathrm{C}^{13}$. J. Chem. Phys., 16: 993.

Stuermer, D. H., Peters, K. E., and Kaplan, I. R. 1978. Source indicators of humic substances and proto-kerogen. Stable isotope ratios, elemental compositions, and electron spin resonance spectra. Geochim. Cosmochim. Acta, 42:989-997.

Venkatesan, M. I., Brenner, S., Ruth, E., et al., 1980. Hydrocarbons in age-dated sediment cores from two basins in the Southern California Bight. Geochim. Cosmochim. Acta, 44:789-802. 
APPENDIX

Chemical Structures Cited
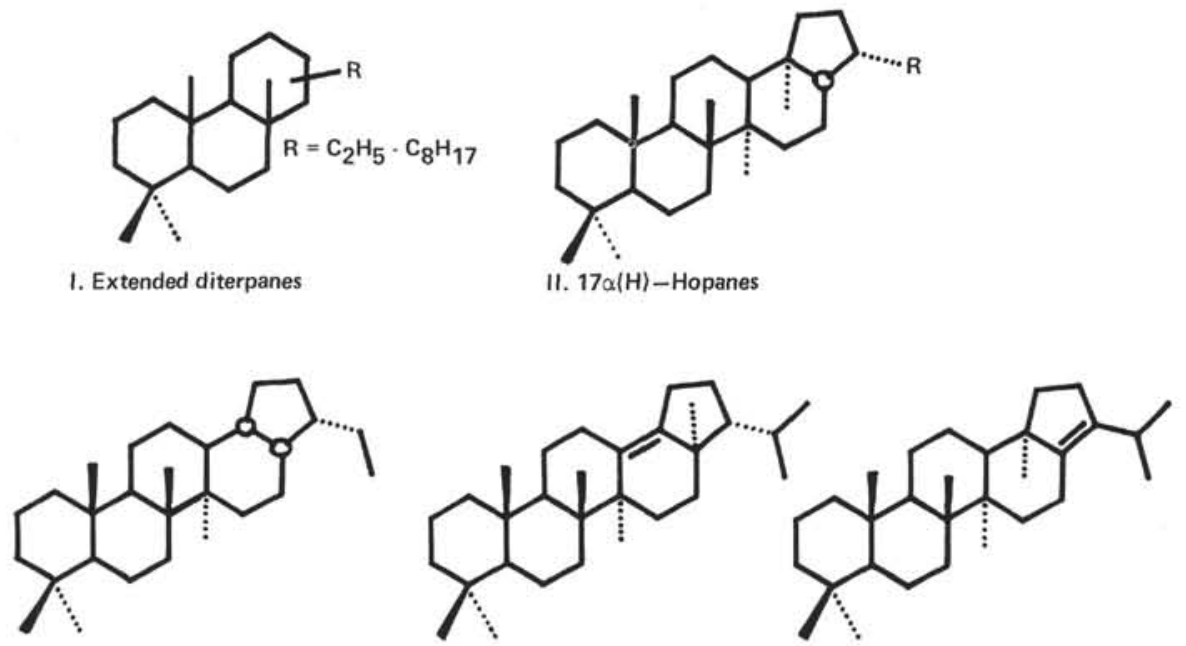

III. $17 \alpha, 18 \alpha, 21 \beta(H)-28,30-$ Bisnorhopane<smiles>CC1(C)C2CCC3[C@]4(C)CCC[C@]5(C)CC[C@@]3(C)C5(C)[C@@]3(C)CCCC3C2CCC14</smiles>

VI. iso-Trisnorhopane

IV. iso - Hop- $13(18)$-ene

V. Hop-17 (21)-ene

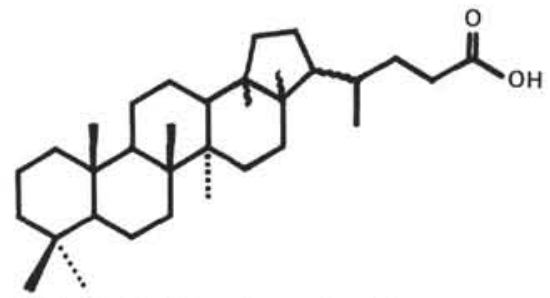

VII. 28-Norbishomohopanoic acid
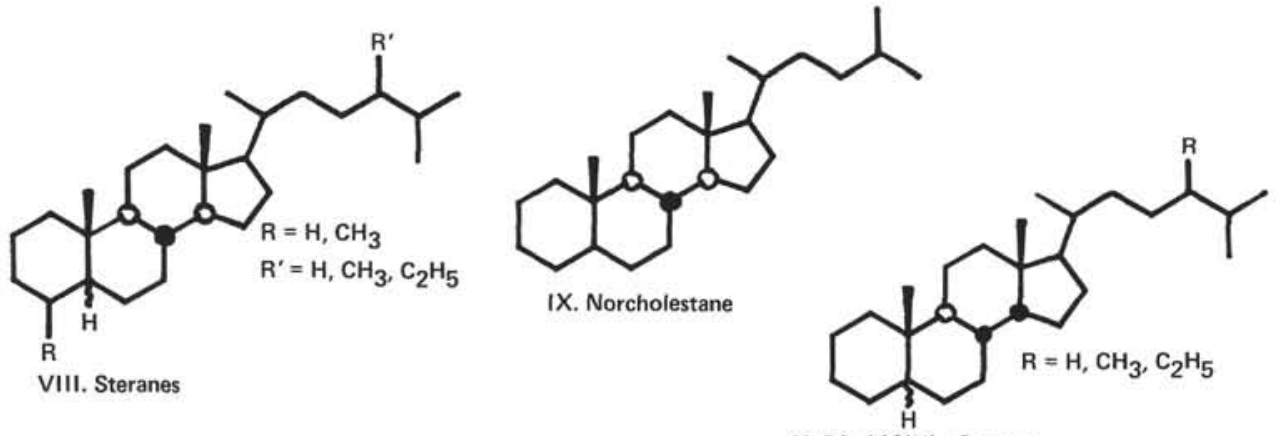

X. $8 \beta, 14 \beta(H)-$ Steranes 